\title{
A MODEL FOR ENERGETICS AND BIOACCUMULATION IN MARINE MAMMALS WITH APPLICATIONS TO THE RIGHT WHALE
}

\author{
Tin Klanjscek, ${ }^{1,3}$ Roger M. Nisbet, ${ }^{2}$ Hal Caswell,${ }^{1}$ and Michael G. Neubert ${ }^{1}$ \\ ${ }^{1}$ Biology Department, MS\#34, Woods Hole Oceanographic Institution, Woods Hole, Massachusetts 02543 USA \\ ${ }^{2}$ Biological Sciences, Ecology, Evolution and Marine Biology, University of California, Santa Barbara, California 93106 USA
}

\begin{abstract}
We present a dynamic energy budget (DEB) model for marine mammals, coupled with a pharmacokinetic model of a lipophilic persistent toxicant. Inputs to the model are energy availability and lipid-normalized toxicant concentration in the environment. The model predicts individual growth, reproduction, bioaccumulation, and transfer of energy and toxicant from mothers to their young. We estimated all model parameters for the right whale; with these parameters, reduction in energy availability increases the age at first parturition, increases intervals between reproductive events, reduces the organisms' ability to buffer seasonal fluctuations, and increases its susceptibility to temporal shifts in the seasonal peak of energy availability. Reduction in energy intake increases bioaccumulation and the amount of toxicant transferred from mother to each offspring. With high energy availability, the toxicant load of offspring decreases with birth order. Contrary to expectations, this ordering may be reversed with lower energy availability. Although demonstrated with parameters for the right whale, these relationships between energy intake and energetics and pharmacokinetics of organisms are likely to be much more general. Results specific to right whales include energy assimilation estimates for the North Atlantic and southern right whale, influences of history of energy availability on reproduction, and a relationship between ages at first parturition and calving intervals. Our model provides a platform for further analyses of both individual and population responses of marine mammals to pollution, and to changes in energy availability, including those likely to arise through climate change.
\end{abstract}

Key words: bioaccumulation; dynamic energy budget (DEB) model; energy intake and utilization; Eubalaena glacialis; lipophilic; marine mammal; North Atlantic right whale growth and reproduction; $P C B$; toxicant transfer.

\section{INTRODUCTION}

In mammals, persistent lipophilic toxicants are bioaccumulated from food and passed to offspring by nursing mothers (Aguilar and Borrell 1994, Restum et al. 1998, Hickie et al. 1999, Ross et al. 2000). This is particularly problematic for marine mammals because of their long life span and their physiological reliance on lipids. The practical challenge is to understand how lipophilic toxicants affect demography as a contribution to developing effective management strategies. This requires models at the individual level that integrate energetics, growth, reproduction, and bioaccumulation. In this paper, we present such a model structured for marine mammals in general. We apply it to the endangered North Atlantic right whale (Eubalaena glacialis), and use it to examine their growth, reproduction, and maternal transfer.

Marine mammals use lipids in their blubber as an energy reserve to mitigate fluctuations in food abun-

Manuscript received 20 March 2006; revised 28 March 2007; accepted 4 April 2007; final version received 4 May 2007. Corresponding Editor: T. E. Essington.

${ }^{3}$ Present address: Institut Rudjer Boskovic, ZIMO, P.O. Box 180, Bijenicka 54, Zagreb, 10002, Croatia.

E-mail: tin@irb.hr dance (Iverson 2002). Lipids accumulate whenever energy intake exceeds expenditures for survival, growth, and reproduction. This accumulation can be significant; the blubber typically constitutes a large fraction of a marine mammal's body mass (e.g., up to $43 \%$ in whales [Lockyer 1976] and 50\% in seals [Iverson 2002]). Energy from the blubber is utilized when energy needs exceed energy inputs (e.g., when starving or reproducing); consequently, the amount of blubber can change significantly from season to season. The rate of change depends upon an individual's energy budget (Reilly 1991).

To build up large energy reserves, individuals must consume large amounts of food. Because toxicants are often bound up with food, they may ingest large amounts of toxicants as well. Persistent lipophilic toxicants accumulate in the blubber, reaching concentrations orders of magnitude greater than those found in the food. For example, Ross et al. (2000) measured concentrations as high as $200-300 \mu \mathrm{g}$ of total polychlorinated biphenyls (PCBs) per gram lipid in the blubber of killer whales feeding on marine mammals (typically $5-50 \mu \mathrm{g} / \mathrm{g}$ ).

Toxicants may have little effect on the individual while sequestered in the blubber (Jørgensen et al. 1999). When an individual uses the energy from the blubber, 
however, the toxicants can be released and may increase mortality (de Swart et al. 1994, Ross et al. 1996, Martineau et al. 2002) or decrease fertility (Reijnders 1986, Schwacke et al. 2002). These effects may involve the effects of the mobilized toxicants on an individual's ability to acquire or utilize energy (Muller and Nisbet 1997).

Toxicants are also transferred from mothers to their offspring through milk, exposing these offspring to toxicants during a critical period in their development. The exposure can have adverse impacts, including negative effects on the immune system (Thomas and Hinsdill 1980) and on cognitive abilities (Guo et al. 2004). The amount of toxicant transfer depends on the mother's energetic status and her toxicant burden which, in turn, depend on the environmental conditions she experienced and the consequential energy acquisition and utilization (including reproduction).

Energy and toxicant dynamics are thus intimately connected. In this paper, we investigate their interaction by coupling an energy budget model to a pharmacokinetic model for the dynamics of the toxicant.

Energy budget models can be classified as either supply- or demand-side models (Klanjscek et al. 2006). In demand-side models, individuals acquire enough energy to satisfy all their energy needs (e.g., von Bertalanffy 1957, Hickie et al. 1999). These models for mammals (e.g., Porter et al. 2000, 2002) focus on adaptations that allow maximum benefit from the consumed food.

To handle variability in food, one needs a supply-side energy budget model in which growth and reproduction depend on the available energy (e.g., Gurney et al. 1990, Hallam et al. 1990, McCauley et al. 1990, Ross and Nisbet 1990, Noonburg et al. 1998, Kooijman 2000, Lika and Nisbet 2000, Nisbet et al. 2000, Gurney and Nisbet 2004 ).

Here, we present a novel energy budget model that takes into account the distinctive requirements of mammalian reproduction. Mammals commit energy to reproduction only during reproductive events, which require substantial, prolonged, and uninterrupted investment of energy. This investment and its success depends on the energy intake and energy reserves of the mother. We couple it to a pharmacokinetic model (related to Boon et al. 1994) and investigate the effects of energy availability on bioaccumulation and vertical transfer of toxicants.

We aim to establish a new theoretical framework for modeling marine mammal energetics using the dynamic energy budget approach which offers a mechanistic link between the environment and individual growth and reproduction. The resulting model is purposely simple, but it has many parameters. As a case study, we focus on a parameter set estimated for the right whale (Eubalaena spp.). The life-history of the right whale is not so unusual as to limit our results to them in particular. In fact, we believe that our results are relevant to many marine mammals. Even though limited in scope, our case study offers interesting results and suggests new hypotheses about bioaccumulation that contradict common wisdom.

We chose the right whale because decreased energy availability and exposure to persistent lipophilic toxicants have been proposed as factors contributing to the decades-long decline in the North Atlantic right whale population growth rate (Knowlton et al. 1994, Fujiwara and Caswell 2001). In the future, we intend to evaluate the significance of these factors relative to others (e.g., ship-strikes and inbreeding). Thus our individual-level model is also a first step toward an individual-based population-level model that can be used to inform conservation decisions.

\section{MOdel Description}

An individual acquires energy needed for its maintenance, growth, and reproduction from the environment. With that energy, the organism acquires toxicants. Both the energy and toxicants are distributed throughout the body. We keep track of these distributions by partitioning the organism into four compartments (Fig. 1): blood (B), structure $(G)$, structural lipids (S), and lipid energy storage (L). We summarize state variables and their units in Table 1; Table 2 contains balance equations using fluxes of energy whose formulae are listed in Table 3. The parameters are estimated for the right whale (see the Appendix) and are listed in Table 4.

\section{Energetics}

We assume that all tissue may be characterized as either "energy reserves" or "structure" (Kooijman 2000). The energy reserves are materials that can be utilized as an energy source for maintenance and growth (e.g., nonstructural lipids, carbohydrates, and proteins). Any tissue the animal cannot utilize for energy during starvation (e.g., bones, structural lipids, etc.) composes the structure. The exact composition of the energy reserves and the structure depend on the species. Some physical tissue, such as muscle, belongs to both energy and structure to some degree: an organism uses muscle protein as energy when starving, but retains some even when it faces death from hunger.

We propose that the energy dynamics of a marine mammal can be captured by focusing on lipid dynamics, as long as the relative amounts of different compounds composing the energy reserves have a constant ratio. For example, muscle protein is depleted in a constant proportion to energy reserves in the blubber during starvation (Nordoy and Blix 1985, Struntz et al. 2004:18). Hence, the dynamics of any component of reserves contains information about other types. We have chosen to keep track of lipids because they are the largest energy reserve in marine mammals, and because lipid dynamics determine the pharmacokinetics of lipophilic toxicants. The proportionality assumption does not hold for some types of energy reserves, e.g., 


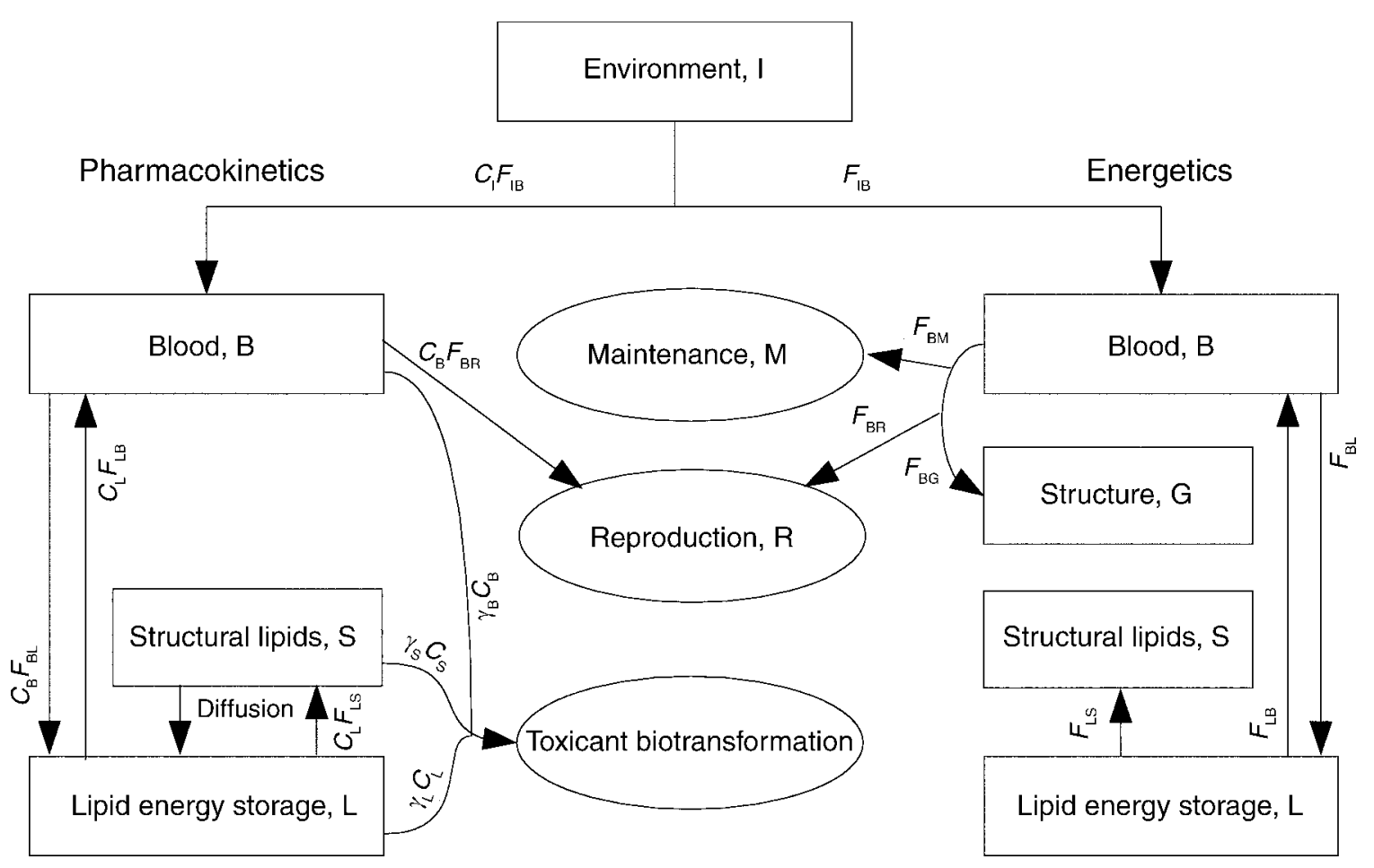

FIG. 1. Model outline with pharmacokinetic (left) and energetic (right) model compartments. Reproduction (R), maintenance metabolism (M), and transformation of toxicants act as sinks for energy, toxicants, or both. Toxicant biotransformation includes all processes that change the molecular form of the modeled toxicant. Arrows for energy and prominent toxicant fluxes are marked with the corresponding symbols.

protein and glycogen. This, however, does not influence overall energy dynamics because such types comprise only a small fraction of standing energy reserves; for example, during starvation $94 \%$ of energy consumption in grey seals (Halichoerus grypus) comes from subcutaneous blubber (Nordoy and Blix 1985).

Lipids, and the tissues that hold them, have multiple functions (Koopman et al. 2002, Struntz et al. 2004). The largest pool of lipids is the blubber, but not all lipids in the blubber are readily metabolized. Lipids in the superficial blubber, i.e., lipids in and beneath the epidermal layer, are barely metabolically active and can be neglected as a source of energy for the organism (Struntz et al. 2004). The metabolic activity of the blubber increases with depth, and deepest layers are most metabolically active (Aguilar and Borrell 1990, Koopman et al. 2002). Recognizing this, we lump all metabolically inert lipids, such as those in the superficial blubber, into the "structural lipids" compartment (S), and all metabolically active lipids, such as those in the middle and deep layers of the blubber, into the "lipid energy storage" compartment (L).

The structure compartment (G) includes all the structure except the structural lipids, and we assume that its composition remains constant through ontogeny. We further assume isomorphic growth, with the implication that the structural volume $(V)$ of the animal is proportional to the cube of some measure of its length. We use $V$ as the state variable representing structure. The blood (B) mediates all transformations of energy and toxicants on short time scales, such as those in the gut and in the liver. Finally, I stands for the environment compartment.

The dynamics of the energetics model is determined by fluxes (rates of flow of energy) between compartments. We denote a flux from compartment $X$ into compartment $Y$ with $F_{X Y}$.

Growth $\left(F_{\mathrm{BG}}\right)$ and maintenance $\left(F_{\mathrm{BM}}\right)$ of structure G.-We assume the energy flux to growth and maintenance is proportional to the lipids available in the blood $\left(E_{\mathrm{B}}\right)$, with a constant of proportionality that characterizes the rate of utilization of lipids, $\beta_{\mathrm{G}}$. Maintenance has

TABLE 1. Compartments and state variables, with units.

\begin{tabular}{clcl}
\hline \hline Abbreviation & Compartment & Energetics & Toxicology \\
\hline $\mathrm{I}$ & environment & $f$ & $C_{\mathrm{I}}(\mathrm{mg} / \mathrm{kg})$ \\
$\mathrm{G}$ & structure & $V\left(\mathrm{~m}^{3}\right)$ & \\
$\mathrm{B}$ & blood & $E_{\mathrm{B}}(\mathrm{kJ})$ & $C_{\mathrm{B}}(\mathrm{mg} / \mathrm{kg})$ \\
$\mathrm{L}$ & lipid energy storage & $E_{\mathrm{L}}(\mathrm{kJ})$ & $C_{\mathrm{L}}(\mathrm{mg} / \mathrm{kg})$ \\
$\mathrm{S}$ & structural lipids & $E_{\mathrm{S}}(\mathrm{kJ})$ & $C_{\mathrm{S}}(\mathrm{mg} / \mathrm{kg})$ \\
$\mathrm{R}$ & reproduction & & \\
$\mathrm{M}$ & maintenance & & \\
\hline
\end{tabular}

Note: $V$ represents volume of the structure, $E$ represents energy in each compartment, and $C$ represents lipid-normalized toxicant concentration. 
TABLE 2. Kinetics: rates of change of state variables.

\begin{tabular}{cl}
\hline \hline Compartment & \multicolumn{1}{c}{ Dynamics } \\
\hline $\mathrm{I}$ & $=$ function of $t$ \\
$C_{\mathrm{I}}$ & $=$ function of $t$ (constant in our simulations) \\
$\frac{d}{d t} V$ & $=\frac{1}{g} F_{\mathrm{BG}}$ \\
$\mathrm{G}$ & $\frac{d}{d t} E_{\mathrm{B}}=F_{\mathrm{IB}}+F_{\mathrm{LB}}-F_{\mathrm{BL}}-F_{\mathrm{BM}}-F_{\mathrm{BG}}-F_{\mathrm{BR}}$ \\
$\mathrm{B}$ & $\frac{d}{d t} C_{\mathrm{B}}=\frac{1}{E_{\mathrm{B}}}\left[C_{\mathrm{I}} F_{\mathrm{IB}}-C_{\mathrm{B}}\left(F_{\mathrm{BL}}+F_{\mathrm{BR}}+\frac{d}{d t} E_{\mathrm{B}}\right)+C_{\mathrm{L}} F_{\mathrm{LB}}\right]-\gamma_{\mathrm{B}} C_{\mathrm{B}}$ \\
$\frac{d}{d t} E_{\mathrm{L}}$ & $=F_{\mathrm{BL}}-F_{\mathrm{LB}}-F_{\mathrm{LS}}$ \\
$\frac{d}{d t} C_{\mathrm{L}}$ & $=\frac{1}{E_{\mathrm{L}}}\left[C_{\mathrm{B}} F_{\mathrm{BL}}-C_{\mathrm{L}}\left(F_{\mathrm{LB}}+F_{\mathrm{LS}}+\frac{d}{d t} E_{\mathrm{L}}\right)\right]-D_{\mathrm{LS}}\left(C_{\mathrm{L}}-C_{\mathrm{S}}\right) V^{2 / 3}$ \\
$\frac{d}{d t} E_{\mathrm{S}}$ & $=F_{\mathrm{LS}}$ \\
$\frac{d}{d t} C_{\mathrm{S}}$ & $=\frac{1}{E_{\mathrm{S}}}\left(C_{\mathrm{L}} F_{\mathrm{LS}}-C_{\mathrm{S}} \frac{d}{d t} E_{\mathrm{S}}\right)+D_{\mathrm{LS}}\left(C_{\mathrm{L}}-C_{\mathrm{S}}\right) V^{2 / 3}$
\end{tabular}

Notes: $V$ represents volume of the structure, $E$ represents energy in each compartment, $C$ represents lipid-normalized toxicant concentration, $F$ represents energy fluxes (equations in Table 4), $D_{\mathrm{LS}}$ is the diffusion coefficient of toxicants between compartments L and $\mathrm{S}, t$ is time, $\gamma_{\mathrm{B}}$ is toxicant decay in the blood (biotransformation rate), and $g$ is the energetic cost of growing structure.

priority; an organism can utilize energy for growth only after it meets the energy requirement for maintenance.

The energy costs of maintenance depend on the size of the organism, and its energy expenditures for foraging and migration. We follow the dynamic energy budget (DEB) theory of Kooijman (2000) and assume that these costs are proportional to the volume of the organism. Hence, the energy flux $F_{\mathrm{BM}}$ required for maintenance of an organism of volume $V$ is

$$
F_{\mathrm{BM}}=m V
$$

where $m$ is the energy required per unit of time to maintain a unit of volume.

The flux of energy to growth, $F_{\mathrm{BG}}$, is the flux possible after maintenance has been met:

$$
F_{\mathrm{BG}}=\left[\beta_{\mathrm{G}} E_{\mathrm{B}}-F_{\mathrm{BM}}\right]_{+}
$$

where $[x]_{+}$is a short-hand notation for $\max (x, 0)$. If the energetic cost of growth by a unit of volume is $g$, the rate of growth of the organism is

$$
\frac{d}{d t} V=\frac{F_{\mathrm{BG}}}{g} .
$$

Energy assimilation $\left(F_{\mathrm{IB}}\right)$.- Only a fraction of the energy intake is assimilated and transported by the blood throughout the body. Hence, the flux of energy from the environment to the blood $\left(F_{\mathrm{IB}}\right)$ depends on food density in the environment, the organism's foraging ability, its ability to process food, and its energy assimilation efficiency. We assume isomorphic growth, so that the energy intake from the environment is proportional to the area of the feeding structures (e.g., surface of the baleen), which is proportional to the surface area of the organism. Then,

$$
F_{\mathrm{IB}}=I_{\max } f V^{2 / 3}
$$

where $I_{\max }$ is the maximum assimilation rate per unit area, and $f$ is a saturating, Type II function of $e_{\mathrm{I}}$, the

TABLE 3. Equations for the energy fluxes.

\begin{tabular}{ll}
\hline \hline \multicolumn{1}{c}{ Flux $(\mathrm{kJ} / \mathrm{yr})$} & \multicolumn{1}{c}{ Description } \\
\hline$F_{\mathrm{IB}}=I_{\max } f V^{2 / 3}$ & intake of energy from the environment into blood \\
$F_{\mathrm{BM}}=m V$ & energy spent on maintenance \\
$F_{\mathrm{BG}}=\left[\beta_{\mathrm{G}} E_{\mathrm{B}}-F_{\mathrm{BM}}\right]_{+}$ & energy utilized for growth $\dagger$ \\
$F_{\mathrm{BL}}=\beta_{\mathrm{L}} E_{\mathrm{B}}$ & energy flux from the blood to the lipid storage \\
$F_{\mathrm{LB}}=\beta_{\mathrm{L}} k_{\mathrm{L}} E_{\mathrm{L}}$ & energy flux from the lipid storage to the blood \\
$F_{\mathrm{LS}}=e_{\mathrm{S}_{0}} \frac{d}{d t} V$ & lipids transformed into structural lipids \\
$F_{\mathrm{BR}}=\frac{1}{k_{\mathrm{R}}}\left(F_{\mathrm{BR}}^{\mathrm{M}}+F_{\mathrm{BR}}^{\mathrm{G}}+F_{\mathrm{BR}}^{\mathrm{E}}\right)$ & flux of energy to reproduction \\
\hline
\end{tabular}

Note: Variables are described in Table 4.

$\dagger[X]_{+}$is a shorthand notation for $\max (0, X)$. 
TABLE 4. Right whale parameter values.

\begin{tabular}{|c|c|c|}
\hline Parameter & Value & Description \\
\hline \multicolumn{3}{|l|}{ Energetics } \\
\hline$\beta_{\mathrm{G}}$ & $52 \mathrm{yr}^{-1}$ & rate of utilization of lipids in blood \\
\hline$\beta_{\mathrm{L}}$ & $365 \mathrm{yr}^{-1}$ & energy conductivity \\
\hline$m$ & $26.5 \times 10^{6} \mathrm{~kJ} \cdot \mathrm{m}^{-3} \cdot \mathrm{yr}^{-1}$ & cost of maintenance of a unit of volume of structure \\
\hline$g$ & $18.4 \times 10^{6} \mathrm{~kJ} / \mathrm{m}^{-3}$ & energetic cost of growing structure \\
\hline$k_{\mathrm{L}}$ & 0.02 & equilibrium ratio constant between blood and lipid storage \\
\hline$I_{\max }$ & $1 \times 10^{8} \mathrm{~kJ} \cdot \mathrm{m}^{-2} \cdot \mathrm{yr}^{-1}$ & energy acquisition rate per biometric area \\
\hline$K_{\mathrm{I}}$ & $4.184 \mathrm{~kJ} / \mathrm{m}^{3}$ & energy intake half-saturation constant \\
\hline \multicolumn{3}{|c|}{ Pharmacokinetics } \\
\hline$\gamma_{\mathrm{B}}$ & $0 \mathrm{yr}^{-1}$ & toxicant decay in the blood (biotransformation rate) \\
\hline$D_{\mathrm{LS}}$ & $0.09 \cdot \mathrm{m}^{-2} \cdot \mathrm{yr}^{-1}$ & diffusion of toxicants between $\mathrm{L}$ and $\mathrm{S}$ \\
\hline \multicolumn{3}{|l|}{ Reproduction } \\
\hline$E_{\mathrm{R}_{\min }}$ & $5.86 \times 10^{8} \mathrm{~kJ}$ & minimum stored energy to start reproduction \\
\hline$\tau_{\mathrm{gest}}$ & $1 \mathrm{yr}$ & length of gestation \\
\hline$\tau_{\text {lact }}$ & $1 \mathrm{yr}$ & length of lactation \\
\hline$a$ & $1.25 \mathrm{~m}^{3} / \mathrm{yr}$ & rate of growth during gestation \\
\hline$\beta_{\mathrm{vB}}$ & $0.35 \mathrm{yr}^{-1}$ & von Bertalanffy rate constant \\
\hline$V_{\max }$ & $52.5 \mathrm{~m}^{3}$ & maximum volume of structure under ideal conditions \\
\hline$k_{\mathrm{R}}$ & 0.7 & efficiency of reproduction \\
\hline \multicolumn{3}{|c|}{ Initial conditions } \\
\hline$e_{\mathrm{S}_{0}}$ & $6276 \mathrm{~kJ} / \mathrm{m}^{3}$ & energy density $\left(E_{\mathrm{S}} / V\right)$ of structural lipids \\
\hline$C_{\mathrm{I}}$ & $0.035 \mathrm{mg} / \mathrm{kg}$ & lipid-normalized intake toxicant concentration \\
\hline
\end{tabular}

environmental energy density:

$$
f=\frac{e_{\mathrm{I}}}{K_{\mathrm{I}}+e_{\mathrm{I}}}
$$

where $K_{\mathrm{I}}$ is the half-saturation constant. Throughout the paper, we refer to $f$ as energy availability. Since every organism has different food types and foraging patterns, the exact meaning of parameters $I_{\max }$ and $K_{\mathrm{I}}$ need to be determined separately for each organism (see Gurney and Nisbet [1998:87] for details). The value of $f$ depends only on the ratio of $e_{\mathrm{I}}$ and $K_{\mathrm{I}}$, so the units and the exact value of $K_{\mathrm{I}}$ do not affect simulations; we therefore fix $K_{\mathrm{I}}$ to $4.184 \mathrm{~kJ} / \mathrm{m}^{3}$.

The energy intake determines the ultimate size of the organism, $V_{\infty}$, and the maximum size of the organism, $V_{\text {max }}$. At $V_{\infty}$, in a hypothetical constant environment and when not diverting energy into reproduction, the organism spends all the acquired energy on maintenance, i.e., $F_{\mathrm{IB}}=F_{\mathrm{BM}}$. From Eqs. 1 and 4,

$$
V_{\infty}=\left(\frac{I_{\max } f}{m}\right)^{3} .
$$

The maximum size is attained for $f=1$ :

$$
V_{\max }=\left(\frac{I_{\max }}{m}\right)^{3} .
$$

Dynamic equilibrium between blood and lipid energy storage $\left(F_{\mathrm{BL}}\right.$ and $\left.F_{\mathrm{LB}}\right)$.- The blood and lipid energy reserves are in direct contact and, therefore, try to equilibrate through exchange of lipids. We assume the flux from one compartment into another depends linearly on the amount of lipids in the origin compartment, and does not depend on anything in the destination compartment. Then, the flux of lipids from $\mathrm{B}$ to $\mathrm{L}\left(F_{\mathrm{BL}}\right)$ and $\mathrm{L}$ to $\mathrm{B}\left(F_{\mathrm{LB}}\right)$ are

$$
\begin{aligned}
& F_{\mathrm{BL}}=\beta_{\mathrm{L}} E_{\mathrm{B}} \\
& F_{\mathrm{LB}}=\beta_{\mathrm{L}} k_{\mathrm{L}} E_{\mathrm{L}} .
\end{aligned}
$$

The net transport of lipids is equal to the difference between the two fluxes.

Growth of structural lipids $S\left(F_{\text {IS }}\right)$.- Structural lipids $\left(E_{\mathrm{S}}\right)$ are part of structure (compartments $\mathrm{G}$ and $\mathrm{S}$ in our model) and cannot be utilized for energy. To satisfy the isomorphism assumption and keep structural lipids in constant proportion to the remaining structure $(V)$, structural lipids have to increase proportionally to increases in $V$ :

$$
\frac{d}{d t} E_{\mathrm{S}}=\frac{E_{\mathrm{S}}}{V} \frac{d}{d t} V .
$$

The biggest pool of structural lipids, the external blubber stratum, is not metabolically active, and does not differ significantly in composition between demographic groups (Aguilar and Borrell 1990). This holds for acoustic fats as well. Structural lipids are typically not significantly vascularized and are, therefore, not metabolically active. This leads us to assume that structural lipids are made from energy storage lipids directly by gradual processes such as de-vascularization, rather than created by material from the blood. Hence, the only flux to the compartment $\mathrm{S}$ is the flux from $\mathrm{L}$ :

$$
F_{\mathrm{LS}}=e_{\mathrm{S}_{0}} \frac{d}{d t} V
$$

where $e_{\mathrm{S}_{0}}=\left(E_{\mathrm{S}} / V\right)$ is the proportion of lipids in the structure of the organism. 
Reproduction $\left(F_{\mathrm{BR}}\right)$.- Mammalian reproduction has two parts: gestation and lactation. We model them separately because they have different modes of energy and toxicant transfers. In gestation, the mother transfers energy and toxicants through the placenta. During lactation, the mother transfers energy and toxicants through milk.

We assume that females start reproducing if, during the reproductive season, the energy in their lipid energy storage is greater than a certain critical value, $E_{\mathrm{R}}$. This assumption is consistent with the observed low variation of lipid storage energy density in female fin whales (Aguilar and Borrell 1990), suggesting that they reproduce upon reaching a certain "trigger" lipid storage energy density. Whether female fin whales accumulate that energy after becoming pregnant, or become pregnant because they have reached the energy density is not clear. Nevertheless, given that onset of ovulation in some mammals depends on their energy reserves (Frisch et al. 1975, Van der Spuy 1985, Frisch 1990, but see Bronson and Manning 1991), that reproductive performance in mammals which experience seasonal food fluctuations depends on energy reserves of mature females (Gopalan and Naidu 1972, Frisch 1978, Lee 1987), and that fin whale fecundity seems to be food-limited (Lockyer 1986), it is plausible to assume that marine mammals trigger ovulation depending on available energy storage. This view is corroborated for right whales by observations (Angell 2005). We assume that there are always enough males present that, upon ovulation, a female is fertilized and becomes pregnant.

The flux of energy to reproduction includes the flux needed for maintenance $\left(F_{\mathrm{BR}}^{\mathrm{M}}\right)$, growth $\left(F_{\mathrm{BR}}^{\mathrm{G}}\right)$, and increase of energy reserves $\left(F_{\mathrm{BR}}^{\mathrm{E}}\right)$ of the young mammal during gestation and lactation:

$$
F_{\mathrm{BR}}=\frac{1}{k_{\mathrm{R}}}\left(F_{\mathrm{BR}}^{\mathrm{G}}+F_{\mathrm{BR}}^{\mathrm{M}}+F_{\mathrm{BR}}^{\mathrm{E}}\right)
$$

where $k_{\mathrm{R}}$ is the reproductive efficiency of utilization of energy, potentially different between gestation and lactation.

We assume that the mother is able to meet all energetic needs of the calf during gestation. We use an empirical model for fetal development commonly used for mammals (Martin and MacLarnon 1985), combined with the assumption that the mass of the fetus is proportional to its volume. According to the model, the volume of the fetus, $V_{\mathrm{F}}$, at time $\tau \geq 0.2 \tau_{\text {gest }}$ since conception is

$$
V_{\mathrm{F}}(\tau)=a\left(\tau-0.2 \tau_{\text {gest }}\right)^{3} .
$$

The volume of the fetus and the rate of change of the volume determine the energy needs of the fetus and, therefore, the mother's energy flux to reproduction.

Total energy flux to reproduction during gestation for $\tau \geq 0.2 \tau_{\text {gest }}$ includes the flux for maintenance of the fetus,

$$
F_{\mathrm{BR}}^{\mathrm{M}}(\tau)=m V_{\mathrm{F}}(\tau)
$$

growth of the fetus,

$$
F_{\mathrm{BR}}^{\mathrm{G}}(\tau)=g \frac{d}{d \tau} V_{\mathrm{F}}(\tau)
$$

and energy transferred to the fetus to build its energy reserves. In our model, the fetus acquires lipid energy reserves throughout gestation even though during fetal development energy is directed mainly towards growth, and lipid energy reserves are developed in the late stages of fetal development (Struntz et al. 2004). Energetically, the timing is not an issue because there is no cost associated with storing reserves, and only the total amount of lipid transferred matters. For the same reason, the timing does not affect estimates of toxicant transfer because the toxicant transfer mainly depends on the total amount of lipids transferred. It may not be a significant issue for estimating gestational exposure either, because the fetus does not experience major bioaccumulation during gestation (the concentration of toxicants in its blood equilibrates with the mother's).

When connecting the energetics of gestation to pharmacokinetics, we assume that there is no placental resistance to toxicant transfer, and therefore the calf's and the mother's concentration of the toxicant in the blood tend to equilibrate. The validity of this assumption is not vital to our model because the bulk of energy (and, therefore, toxicant) is transferred during lactation (Young 1976). However, if exposure during fetal development is of concern, a more detailed model of fetal development, including the transport of lipids and toxicants across the placenta, may be required.

We assume that energy in the blood of the fetus is just sufficient to provide the energy flux for maintenance, and that the energy in the lipid energy storage compartment is in a dynamic equilibrium with the lipids in the blood:

$$
\begin{aligned}
& E_{\mathrm{B}}^{\text {Fetus }}=\frac{1}{\beta_{\mathrm{L}}} F_{\mathrm{BR}}^{\mathrm{M}} \\
& E_{\mathrm{L}}^{\text {Fetus }}=\frac{1}{\beta_{\mathrm{L}} k_{\mathrm{L}}} F_{\mathrm{BR}}^{\mathrm{M}} .
\end{aligned}
$$

The energy flux from the mother required to satisfy Eqs. 16 and 17 and the increase in the structural blubber, for $\tau \geq 0.2 \tau_{\text {gest }}$, is the energy needed to increase energy pools of the fetus proportionally to the change in volume:

$$
\begin{aligned}
F_{\mathrm{BR}}^{\mathrm{E}} & =\frac{d}{d t}\left(E_{\mathrm{B}}^{\text {Fetus }}+E_{\mathrm{L}}^{\text {Fetus }}+E_{\mathrm{S}}^{\text {Fetus }}\right) \\
& =\left[\frac{1}{\beta_{\mathrm{L}}}\left(1+\frac{1}{k_{\mathrm{L}}}\right) m+e_{\mathrm{S}_{0}}\right] \frac{d}{d \tau} V_{\mathrm{F}}(\tau) .
\end{aligned}
$$

After birth, a newborn depends exclusively on its mother's milk for energy until weaning (Thomas and Taber 1984). During nursing, there are two competing processes: what the nursling demands and what the 
mother can give. The energy transferred is equal to the lesser of the two after adjusting for the inefficiencies of milk production and nursing. We assume that the nursling has an "ideal energy demand" which would allow it to grow following the von Bertalanffy growth curve, $V_{\mathrm{vB}}(t)$, with its ultimate goal to reach the maximum volume observed for the species $\left(V_{\max }\right)$. The energy flux required to meet the target growth curve $V_{\mathrm{vB}}(t)$ is the sum of energy fluxes needed for maintenance, growth and increasing energy reserves of the nursling:

$$
\begin{aligned}
& F_{\mathrm{BR}}^{\mathrm{M}}=m V_{\mathrm{vB}}(t) \\
& F_{\mathrm{BR}}^{\mathrm{G}}=g \frac{d}{d t} V_{\mathrm{vB}}(t) \\
& F_{\mathrm{BR}}^{\mathrm{E}}=\left(e_{\mathrm{B}_{0}}+e_{\mathrm{L}_{0}}+e_{\mathrm{S}_{0}}\right) \frac{d}{d t} V_{\mathrm{vB}}(t) .
\end{aligned}
$$

Here we assume that the nursling tries to match the energy density of its mother at conception, $e_{\mathrm{B}_{0}}$ in the blood, and $e_{\mathrm{L}_{0}}$ in the lipid storage compartment.

Using our model, we calculate the growth of the nursling from its actual energy assimilation, which is the minimum between the ideal energy demand and what the mother can provide. When the mother is not able to meet the ideal energy demand, the nursling receives less than the ideal energy flux. If this flux combined with the nursling's energy reserves is not sufficient to meet the maintenance requirements of the nursling, the nursling dies.

\section{Pharmacokinetics}

Our pharmacokinetic model keeps track of lipidnormalized concentrations of toxicants in an individual (Table 1) by modeling the biotransformation and movement of lipophilic toxicants between compartments of the organism. Unless otherwise mentioned, all concentrations are lipid-normalized, expressed in milligrams of toxicant per kilogram of lipid (mg/ $\mathrm{kg}$ ). Upon entering the blood, the toxicants can either be biotransformed (e.g., hydroxylated [Borga et al. 2004]), or transported throughout the body.

With the exception of the compartment $G$ (structure without structural lipids), compartments in the pharmacokinetic model correspond to those of the energetics model. The compartment $\mathrm{G}$ is not directly involved in the toxicant dynamics because it does not include any lipids.

Lipophilic toxicants are not completely free to diffuse between compartments, nor are they all covalently bound to the lipids. Therefore, the transport of toxicants between compartments is a mixture of passive transport where toxicants behave as if they were not bound at all to the lipids, and lipid-facilitated transport where toxicants behave as if they were covalently bound to the lipids. We model both modes of transport.
Facilitated transport is assumed to be completely controlled by the fluxes of energy in the energetics model: the toxicant flux from one compartment to another is proportional to the concentration of the toxicant in the source compartment and the flux of lipids from the source to the destination compartment. We assume no barriers to facilitated toxicant transport between compartments.

Passive transport involves the diffusion of toxicants between compartments. Diffusion rate is proportional to the difference in concentrations of toxicants, and to the boundary area between the compartments (Crank 2004) which, in view of our assumption of an isomorphic animal, is assumed proportional to $V^{2 / 3}$. Therefore, the rate of change of concentration of toxicants in compartments $X$ and $Y$ due to diffusion is

$$
\frac{d}{d t} C_{Y}=-\frac{d}{d t} C_{X}=D_{X Y}\left(C_{X}-C_{Y}\right) V^{2 / 3} .
$$

Regardless of the method of transport, we assume the toxicants redistribute within compartments instantaneously, i.e., the concentration within any compartment is uniform.

Although the model can account for biotransformation of toxicants in all compartments (Fig. 1), the rates of biotransformation in the blood compartment are higher than in other compartments (Boon et al. 1992, Borga et al. 2004). Furthermore, the other compartments communicate with the blood on time-scales much shorter than rates of biotransformation in those compartments. Therefore, we can simplify the model by assuming that only the biotransformations of the toxicants in the blood (e.g., by liver, gut, and vascular endothelia) are significant. We represent these biotransformations as a sink of toxicants: when biotransformed, toxicants are lost from the model.

Aside from the dilution by growth (proportional to $-C_{X}(d / d t) E_{X}$ for compartment $X$ ), the rate of change of toxicant concentration of any compartment is determined by its sources, sinks, and passive and/or facilitated exchange of toxicants with other compartments. We do not model feedback of contaminants on rate processes (e.g., Leung et al. 1990a,b), but such feedback could be incorporated if necessary. The environment is the original source of all the accumulated toxicants.

Because of our choices of units motivated by the literature, we need a conversion factor $\eta$ to connect fluxes of energy $(\mathrm{kJ} / \mathrm{yr})$ to fluxes of lipids $(\mathrm{kg} / \mathrm{yr})$. The factor has units of $\mathrm{kg}$ lipid per $\mathrm{kJ}(\mathrm{kg} / \mathrm{kJ})$. We do not need to know its value, as it cancels out in the equations for rates of change of toxicant concentrations (Table 2).

Blood compartment $(B)$. - We assume that toxicants in the blood experience both facilitated and passive transport to and from lipid energy storage. Fluxes of lipids to and from the blood compartment are both large, even when the standing stocks $\left(E_{\mathrm{B}}, C_{\mathrm{B}}\right)$ are small. Because of this, we assume that the dominant mode of 
transport of toxicants between the blood and the lipids is facilitated and ignore passive toxicant transport in and out of the blood compartment. Facilitated transports include the environmental input $\left(\eta C_{\mathrm{I}} F_{\mathrm{IB}}\right)$, the exchange with the lipid energy storage $\left(\eta\left(C_{\mathrm{L}} F_{\mathrm{LB}}-C_{\mathrm{B}} F_{\mathrm{BL}}\right)\right)$ and a sink: reproduction $\left(-\eta C_{\mathrm{B}} F_{\mathrm{BR}}\right)$.

Additional sinks include biotransformation $\left(-\gamma_{\mathrm{B}} C_{\mathrm{B}}\right)$, urinary excretion, and respiratory exchange. Urine is not rich in lipids and, according to our assumptions, cannot be a large sink for non-metabolized lipophilic toxicants. Breathing is potentially both a source and a sink; we assume, however, that the respiratory exchange of lipophilic toxicants is much smaller than the nutritional input and can, therefore, be ignored. Hence, we ignore urinary excretion and respiratory exchange because we deem them not important, cannot parameterize them reliably, and account for them (at least partially) through biotransformation. These processes can be included in the model at a later date if necessary. Note that fecal excretion is accounted for by the assimilation efficiency (which is assumed equal to the assimilation efficiency of energy): some lipids pass through the digestive system, and so do the toxicants associated with them.

Lipid energy storage (L).-Facilitated transport includes transfers between the lipid energy storage and the blood $\left(\eta\left(C_{\mathrm{B}} F_{\mathrm{BL}}-C_{\mathrm{L}} F_{\mathrm{LB}}\right)\right)$ and a sink from the toxicant flux associated with the growth of the structural lipids $\left(-\eta C_{\mathrm{L}} F_{\mathrm{LS}}\right)$. Passive transport consists of the diffusion between the two types of lipids $\left(-D_{\mathrm{LS}}\left(C_{\mathrm{L}}-\right.\right.$ $\left.C_{\mathrm{S}}\right) V^{2 / 3}$ ).

Structural lipids $(S)$.- Since the structural lipids are created from the energy storage lipids, their exchanges of toxicants include only the flux from the energy storage lipids during creation of structural lipids $\left(\eta C_{\mathrm{L}} F_{\mathrm{LS}}\right)$ and diffusion with the energy storage lipids $\left(D_{\mathrm{LS}}\left(C_{\mathrm{L}}-C_{\mathrm{S}}\right) V^{2 / 3}\right)$. Additional losses of toxicants could include losses through shedding of skin. We did not find evidence that shedding comprises a big sink, and thus ignored it.

\section{The Right Whale}

There are three species of right whales: the North Pacific (Eubalaena japonica), the North Atlantic (Eubalaena glacialis), and the southern (Eubalaena australis) right whale (Rosenbaum et al. 2000). There are possibly additional stocks within these populations (North Atlantic Right Whale Recovery Team 2000). Prior to the ban on right whale hunting in 1935 (Convention 1931), all right whales had been commercially exploited and brought to dangerously low levels. The southern right whale recovered since the ban and exhibits a yearly population growth rate of more than $7 \%$ (Best et al. 2001). The recovery of the North Pacific right whales seems to be threatened by illegal hunting, but more research is needed to quantify their status (Brownell et al. 2001). The North Atlantic right whale population was hunted down from as many as 1900 whales in 1630 to as few as 50 in the 1800 s (Reeves et al. 1992). Since the ban on hunting, it has recovered to the estimated 300 individuals today (Kraus et al. 2001). In spite of this small recovery, the Northern Atlantic right whale seems to be declining again with an increasing rate. If these trends persist, the North Atlantic right whale is expected to go extinct in about 200 years (Fujiwara and Caswell 2001). Some insight into demographic reasons for the continuing decline can be gained by comparing the North Atlantic whales with their southern cousins: the North Atlantic right whale has twice the mortality rate, while their calving interval is almost double that of the southern right whale (Best et al. 2001, Brunell 2001, Kraus et al. 2001).

Whereas gear entanglement and ship strikes account for most of the higher mortality in the North Atlantic population, and reducing these causes may be necessary for recovery of the population, it is also important to understand why the calving interval is so long. The reason may be the fact that right whales need large amounts of energy for growth, maintenance and reproduction, which may not be available in the environment. They also may be at risk from toxicants because, even though right whales are not high in the food chain because they feed mainly on zooplankton, their lipid-rich nature and marine mammal life history makes them potentially vulnerable to persistent bioaccumulating compounds such as PCBs. Therefore, a combination of nutritional stress and exposure to toxicants may be increasing the interval between successful reproductions and reducing the fertility (Knowlton et al. 1994, Angell 2005).

Right whales can also experience additional hazards due to starvation-induced exposure when inactive toxicants stored within the lipids get mobilized as the lipids get utilized (Aguilar et al. 1999). This is of a particular concern because right whales fast during a part of the year (Best and Schell 1996) and nutritional stress could interact with such exposure to further degrade growth and reproduction of individuals.

We describe the details necessary to adapt the model to the right whales and estimate the parameters in the Appendix. The parameter values are listed in Table 4.

\section{RESUlts \\ Growth and reproduction}

To investigate the dependence of growth and reproduction on energy intake in right whales, we look at the growth and reproduction in a constant environment, and investigate the consequences of seasonal fluctuations and starvation. Unless otherwise noted, all plots are of a first-generation, first-born individual. This is necessary because our model needs energy input during gestation and nursing of one generation, which requires a mother from a prior generation. We simulate the zerogeneration mother by initializing the model from her weaning. We used the whale MH-89-424-Eg from Moore et al. (2005) to estimate her initial conditions 


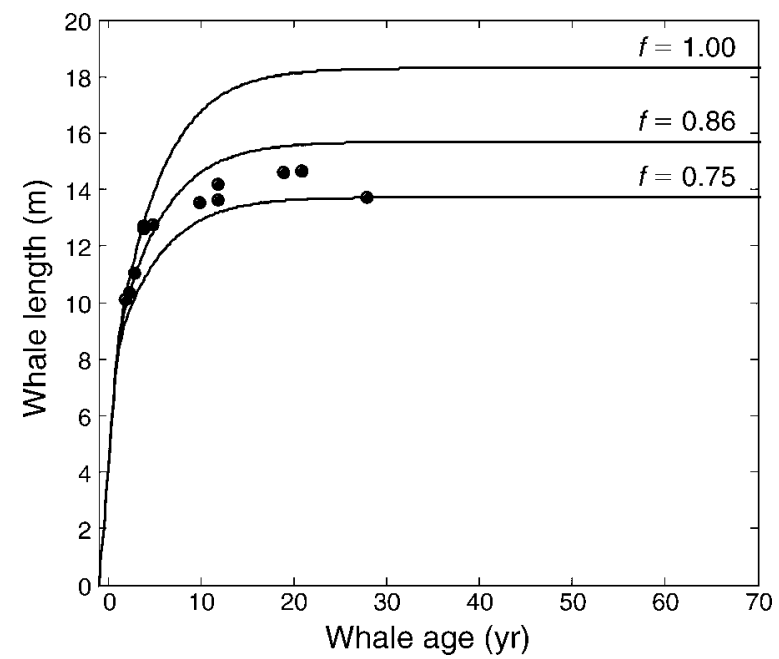

FIG. 2. Length of nonreproducing right whales as a function of age for a range of energy availability, $f$. Solid circles represent data for individuals older than one year; data are from Moore et al. (2005).

$\left(V(0)=1 \mathrm{~m}^{3}, E_{\mathrm{L}}(0)=7.78 \times 10^{6} \mathrm{~kJ}, E_{\mathrm{B}}(0)=4.184 \mathrm{~kJ}\right.$, no burden).

To investigate growth, we calculate the length of a non-reproducing individual as a function of age for values of the scaled functional response $f$, a measure of energy availability defined by Eq. 5, ranging from $f=$ 0.75 to $f=1$ (Fig. 2). The data from Moore et al. (2005), for individuals older than 1 year, fall within the sizes predicted for the range in $f$. Using Eq. 6, the observed ultimate size of about $14.5 \mathrm{~m}$ suggests that an appropriate value of $f$ for the North Atlantic right whale would be around 0.8 . This is an underestimate, as it does not take into account the energy spent on reproduction.

To account for the energy spent on reproduction, we use observed calving interval of about five years (Kraus et al. 2001) to estimate $f$ in the North Atlantic, $f_{\text {NA }}$. Fig. 4 shows the mean interval between reproductive events of a first-generation mother over a 100-year period for a range of energy availability. Comparison between the calculated and observed calving intervals suggests that $f_{\mathrm{NA}}=0.9$. A reproductively active female experiencing $f_{\mathrm{NA}}$ grows to the same size as a non-reproducing female experiencing $f=0.8$ (Fig. 3). Thus we set $f=0.9$ in all simulations unless otherwise noted.

According to the model, an increase of only $10 \%$ in $f$, representing an order of magnitude increase in $e_{\mathrm{I}}$ for the given (underestimated) $I_{\max }$, would decrease the calving interval of the North Atlantic right whales to three years, equal to that of their southern cousins. Furthermore, the age at first parturition, which includes the gestation period of the first calf, decreases from the predicted seven years to six years for the same change in $f$.

A whale's response to seasonal environmental variability may influence reproduction. The energy avail- ability, $f$, is a Type II functional response of $e_{\mathrm{I}}$, the energy density available in the environment (see Eqs. 4 and 5) which, in turn, depends on the season and the location of the right whale. Rather than trying to capture the intricate and fairly poorly understood typical yearly energy availability pattern of the North Atlantic right whales (see Winn et al. 1986, North Atlantic Right Whale Recovery Team 2000), we assumed that the energy density in the environment experienced by the individuals oscillates sinusoidally. This corresponds to the assumption that there is a season of food abundance, a season of food scarcity, and two transitional seasons. Since the functional response $f$ is determined by the ratio of $e_{\mathrm{I}}$ and the half-saturation constant $K_{\mathrm{I}}$, we did not have to determine $K_{\mathrm{I}}$ explicitly. Instead, we wrote $f$ in terms of $e_{\mathrm{I}} / K_{\mathrm{I}}$. Then, inserting the sinusoidal environmental forcing, $e_{\mathrm{I}} / K_{\mathrm{I}}=\alpha[1+\sin 2 \pi(t+$ $\phi)$ ], and rearranging gives:

$$
f(t)=\frac{\alpha[1+\sin 2 \pi(t+\phi)]}{1+\alpha[1+\sin 2 \pi(t+\phi)]}
$$

where $\phi$ is the phase shift of the sinusoid relative to breeding season, and $\alpha$ the amplitude of oscillations. For each simulated $\alpha$, we calculated average energy availability, $f_{\alpha}=\int_{0}^{1} f(t) d t$, and compared first parturition times and calving intervals to those of constant energy availability $f=f_{\alpha}$ (Fig. 4). We use $\phi=0.5 \mathrm{yr}$ in the simulations, corresponding to the assumption that mothers give birth at the onset of food scarcity. This assumption is consistent with the observations (Winn et al. 1986). When the onset of food abundance happens at the start of the breeding season $(\phi=0 \mathrm{yr})$, first parturition times and calving intervals are significantly longer for low $f_{\alpha}$. Generally, simulations suggest that seasonal oscillations increase the calving interval and time to maturity, but the effect is small for large $f$ (Fig. 4).

The energy budget of individuals changes during growth and reproduction. In simulations, an individual

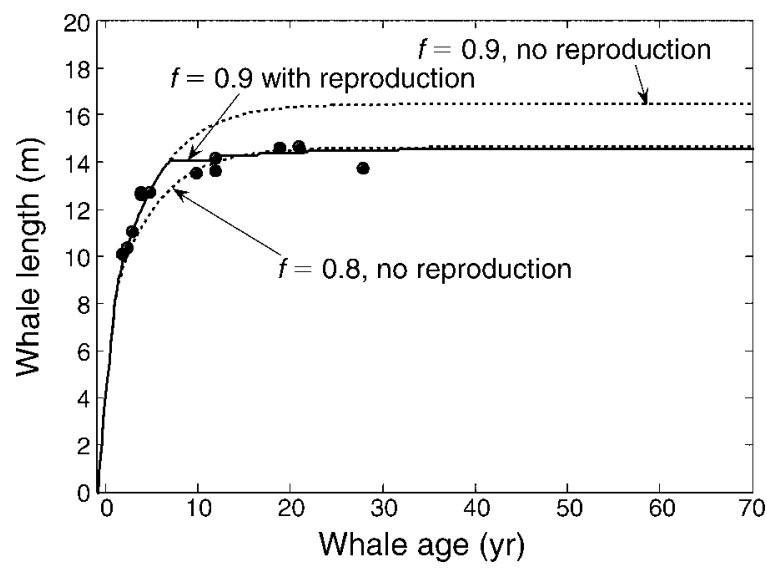

FIG. 3. Influence of reproduction on growth. Reproducing females (solid line) experiencing $f=0.9$ grow to the same size as nonreproducing females (dotted lines) experiencing $f=0.8$. 


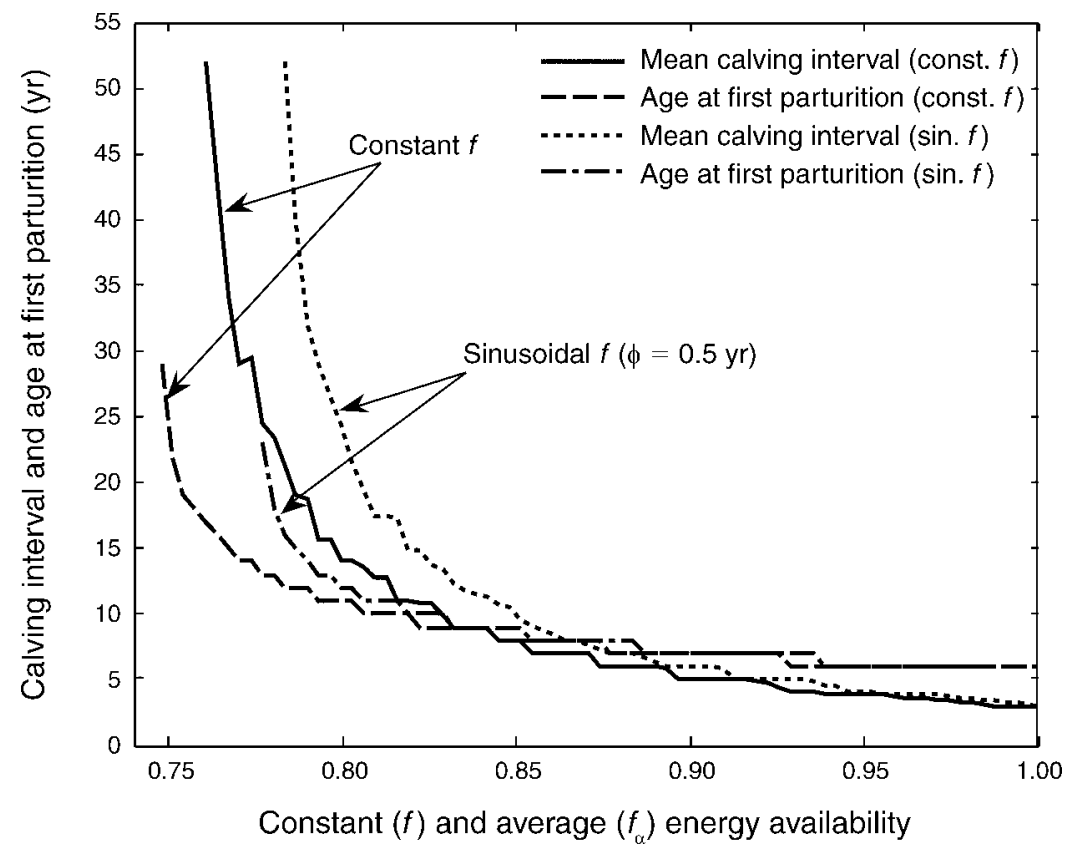

FIG. 4. Calving interval averaged over simulation time, and age to maturity for a range of average energy availability $(f)$, constant (const.) and sinusoidal ( $\sin$.). The seasonally variable $f(t)$, described by Eq. 24 , has an average of $f_{\alpha}$, a period of one year, and a phase shift relative to a breeding season $(\phi)$ of 0.5 years.

has the largest energy storage density $\left(e_{\mathrm{L}}=E_{\mathrm{L}} / V\right)$ at weaning (Fig. 5A, B). This surplus energy gets utilized for growth after weaning; the growth rates decrease once that additional energy received from the mother is depleted. The model predicts that reproductively active females are smaller than males of the same age because females stop growing during reproductive events (Fig. 5A). A reproductive signal is noticeable even in the fluctuating environment, with the females spending about $55 \%$ of their energy storage on reproduction when $f=f_{\mathrm{NA}}$, and only about $39 \%$ when $f$ is $10 \%$ higher. Therefore, a relatively small increase in energy intake $\left(F_{\mathrm{IB}}\right)$ not only substantially decreases the calving interval, but also reduces the stress (in terms of energy loss) on the mother as well. Consistent with observations (J. Moore, personal communication), the model predicts that an adult male dies of complete starvation (e.g., because it cannot feed due to entanglement in fishing gear) in a little less than eight months (not shown).

An interesting consequence of the dynamic energy budget predicted by the model is the possibility of a calving interval hysteresis: the calving interval depends not only on energy availability, but also on the history of energy availability. If there is a long-term decrease in $f$, the calving interval of females that have grown up during higher $f$ will be longer than that of females which have matured during lower $f$. For example, if $f$ decreases from $1.1 f_{\mathrm{NA}}$ (three year calving intervals) to $f_{\mathrm{NA}}$ when the female is 20 years old, her average calving interval increases to 6 years, rather than 5 years, as it would be had she experienced $f_{\mathrm{NA}}$ all of the time. This means that, depending on its duration, high energy availability could have negative long term consequences on a population if it is followed by a stretch of low energy availability because it may take a whole generation until the population optimally utilizes the lower energy availability. Furthermore, when the energy availability is extremely low, smaller mature females are able to take better advantage of a sudden increase in energy availability. Both of these effects are a consequence of higher maintenance requirements of longer females. When the energy is readily available, bigger size is advantageous because it helps take advantage of the available energy, but when the energy is scarce, smaller size is more desirable because lower maintenance costs leave more energy available for reproduction.

\section{Toxicant distribution and vertical transfer}

Energy dynamics drives bioaccumulation and distribution of toxicants. We assumed that toxicants are introduced into the organism exclusively through energy assimilation, excreted exclusively through reproduction, and biotransformed exclusively in the blood compartment. Initially, we ignore biotransformation $\left(\gamma_{B}=0\right)$.

When energy and toxicant in the environment are constant, concentrations of toxicants in all types of lipid follow a similar pattern of bioaccumulation (Fig. 5C). Nurslings bioaccumulate toxicants rapidly because they ingest milk with high concentration of toxicants, use some of the energy from the milk for maintenance and growth, but have no way of excreting the toxicants. Toxicant concentrations of the calves peak at weaning 

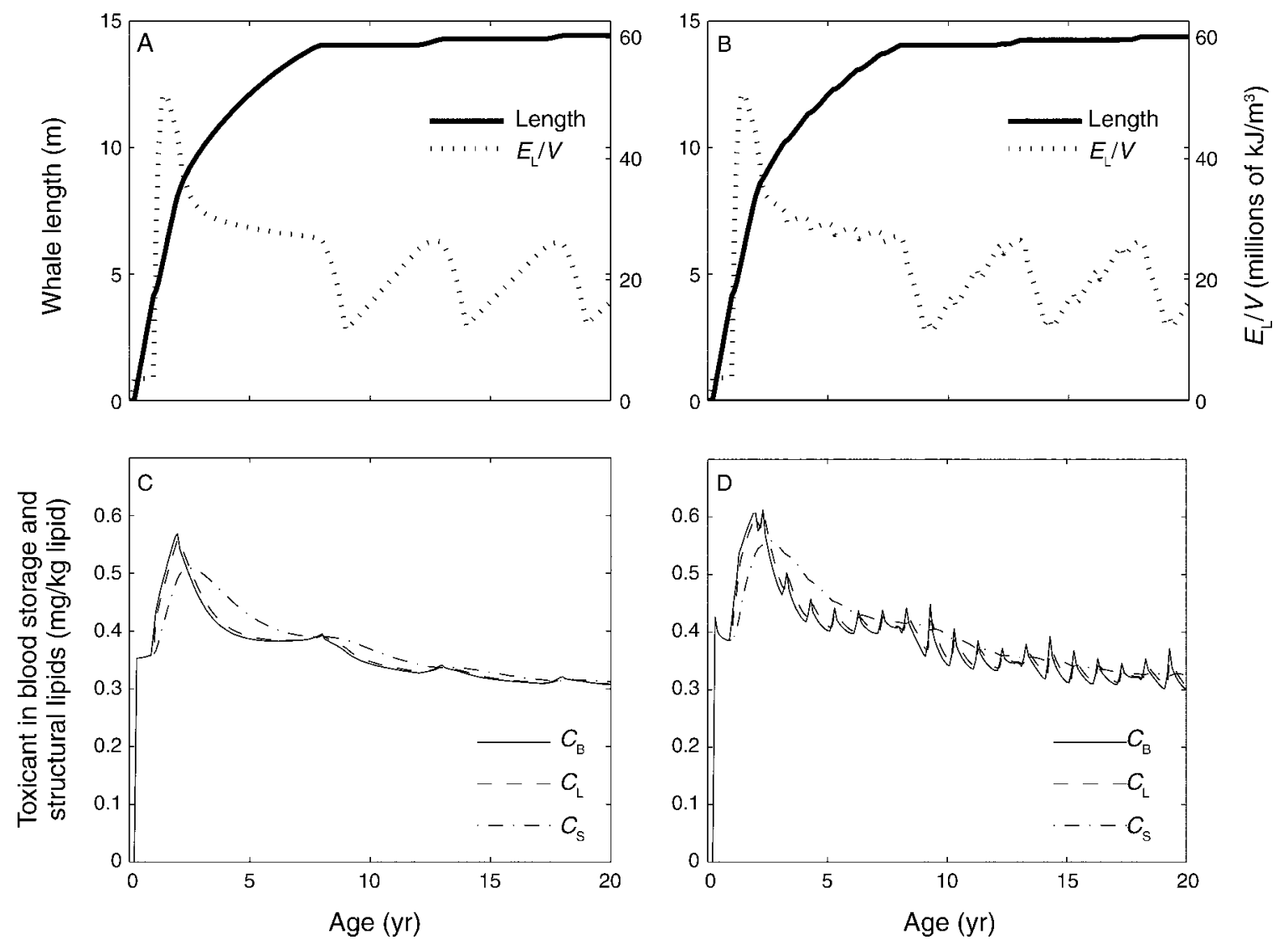

FIg. 5. Energy and toxicant distribution for a female in a constant (panels A and C) and fluctuating (panels B and D) environment. The energy assimilation in the fluctuating environment is described by Eq. 24 and has an average of $f_{\mathrm{NA}}$, our estimate of energy availability experienced by the North Atlantic right whale. (A and B) Length and energy stored per unit of structural volume $\left(E_{\mathrm{L}} / V\right)$ in relation to age. $(\mathrm{C}$ and $\mathrm{D})$ Concentration of toxicants in the blood $\left(C_{\mathrm{B}}\right)$, lipid energy storage $\left(C_{\mathrm{L}}\right)$, and structural lipids $\left(C_{\mathrm{S}}\right)$, shown as $\mathrm{mg}$ toxicant $/ \mathrm{kg}$ lipid, in relation to age.

and then decrease due to dilution of toxicants by ingestion of lipids with relatively low environmental toxicant concentrations.

Energy budget dynamics in a variable environment result in toxicant concentration differences between compartments (Fig. 5D). When the energy assimilation rate is high, the organism stores the ingested lipids and dilutes the toxicants in the blood, as well as in the lipid energy storage. When the energy assimilation is low, the organism is starving and drawing lipids and toxicants from the lipid energy storage. Since lipids are used for maintenance, toxicants accumulate in the blood. This starvation-induced exposure is clearly visible as peaks of concentration in blood and lipid energy storage. As $f$ oscillates, the concentrations in the blood and the lipid energy storage follow with a phase lag. The phase lag of concentration oscillations in the blood is about a month less than that of lipid energy storage. Due to the diffusive nature of exchange of toxicants between the structural and energy storage lipids, structural lipids act as a low-pass filter: since $C_{\mathrm{S}}$ always tends to equilibrate with $C_{\mathrm{L}}$, but does so slowly, $C_{\mathrm{S}}$ reflects only trends in $C_{\mathrm{L}}$. Complete starvation (e.g., due to entanglement in fishing gear) can increase $C_{\mathrm{B}}$ by an order of magnitude (not shown).

After the females mature, they export toxicants through reproduction. Females are predicted to lose about $40-45 \%$ of their toxicant burden during a reproductive event, consistent with about a 53\% loss estimated during 18 months of nursing in beluga whales (Hickie et al. 2000). Reproduction is not completely efficient because mothers discard tissue (e.g., placenta) and a proportion of the mother's milk is excreted by the calf. These inefficiencies (parameterized by $k_{\mathrm{R}}$ ) imply that calves assimilate only $70 \%$ of the burden lost by the mother, or about $30 \%$ of mother's initial burden.

The bulk of (potential) decrease in concentration of the toxicants in the mother's tissue comes from dilution after the reproduction event, rather than loss of toxicants during reproduction. During reproduction, the energy transferred has almost the same concentration of toxicants as the lipid storage. Therefore, the concentration of toxicants in all the mother's compartments is roughly constant for the duration of the reproductive event. After the reproductive event, the mother ingests and stores lipids from the environment 


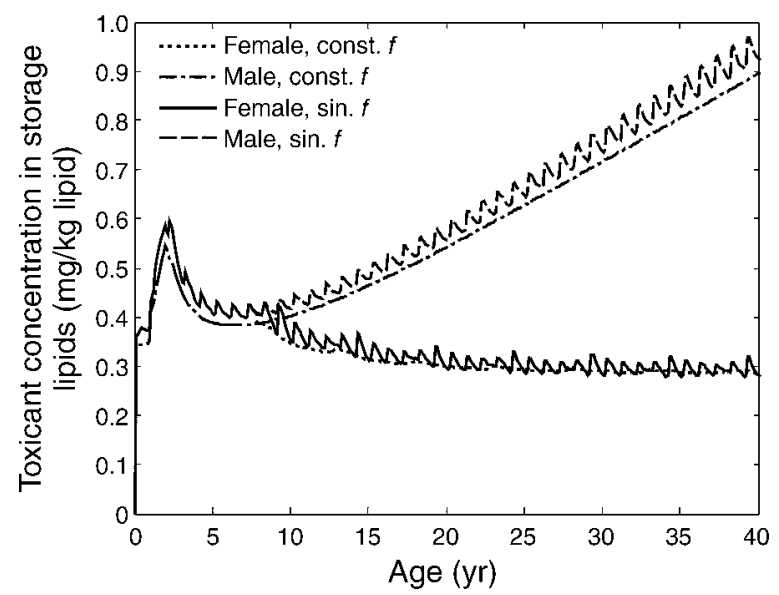

FIG. 6. Male and female right whale toxicant bioaccumulation in energy storage lipids $\left(C_{\mathrm{L}}\right)$ with age, in constant (const.) and seasonal (sinusoidal, sin.) environments; $f=f_{\alpha}=f_{\mathrm{NA}}$.

with a lesser toxicant concentration than her own, thus diluting the toxicant and reducing the concentration in her lipids. This may not happen when the energy availability is low and the rate of bioaccumulation is greater than the rate of dilution.

For a grown female in a constant or seasonally varying environment, the export of toxicants during reproduction and the bioaccumulation between two reproductive events effectively equilibrate after a few reproductive events. The export is larger the larger the burden, while bioaccumulation between two reproductive events remains constant. Hence, if the export during a reproductive event is greater than the toxicants accumulated between two reproductive events, females experience a reduction of their toxicant burden. If the export is smaller than the bioaccumulation, the burden increases. Eventually, the two are practically equal. Hence, in the long run, the toxicant transfer is determined by the difference between bioaccumulation and reproductive loss. The mother's history of prepubescent exposure is, therefore, reflected only in the first few reproductive events, and the transfer of toxicants to the next generation after those few events is practically the same regardless of the mother's pharmacokinetic history. In Fig. 5C, toxicant transfer is close to equilibrating by the third or fourth reproductive event.

The calculated pattern of bioaccumulation is consistent with the commonly assumed marine mammal patterns and observed PCB concentrations in North Atlantic right whales and other marine mammals (Lee et al. 1996, Ross et al. 2000, Weisbrod et al. 2000: Fig. 2, top right plot). Weisbrod et al. (2000) measured lipidnormalized prey concentrations of PCBs between 0.01 $\mathrm{mg} / \mathrm{kg}$ and $0.4 \mathrm{mg} / \mathrm{kg}$, and right whale blubber concentrations between 0.1 and $8 \mathrm{mg} / \mathrm{kg}$. This suggests that bioaccumulation amplifies the environmental con- centration by an order of magnitude, consistent with our predictions.

Even though the accumulation of toxicants in both males and females is greater in seasonally variable environments, there are significant differences between male and female patterns of accumulation (Fig. 6). For example, a 30-year-old male is larger than a female of the same age and has more than double the concentration of toxicants. The large difference between toxicant concentrations in male and female right whales can only be attributed to vertical toxicant transfer from the mother to her calf during gestation and lactation.

The mass of toxicant transferred correlates with the calving interval (especially for second- and later-born calves) and depends on the birth order of the calf (Fig. 7). For large energy availability, the firstborn calf can get as much as twice the burden the subsequent calves get because its mother accumulated a large burden through nursing and maintenance requirements during nursing. However, if food is low, the calving interval is large and the toxicant has an opportunity to bioaccumulate to a greater extent in the interval between the calves than before the first calf. Then, the transfer of toxicants increases with birth order. For the values of $f$ currently experienced by the right whales, toxicant transferred decreases with birth order.

Because there were no data available, we assumed a low but arbitrary proportion of structural blubber $\left(e_{\mathrm{S}_{0}}\right)$, and for simplicity we set the rate of biotransformation of toxicants $\left(\gamma_{B}\right)$ to zero in our simulations. To better understand how these parameters influence the analyses, we repeated simulations for a range of values of $e_{\mathrm{S}_{0}}$ and $\gamma_{\mathrm{B}}$.

The proportion of structural blubber does not significantly influence time to maturity, calving interval, or vertical transfer of toxicants when structural lipids constitute less than $5 \%$ of the total lipids $\left(e_{\mathrm{S}_{0}}<2.1 \times 10^{6}\right.$ $\mathrm{kJ} / \mathrm{m}^{3}$ ). The effects are moderate when the structural

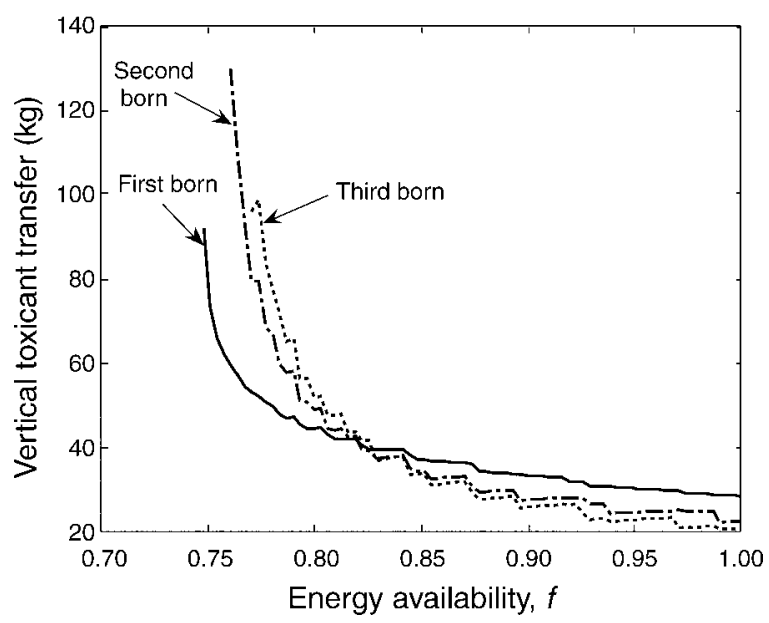

FIG. 7. Toxicant transferred to first, second, and third born for a range of energy availabilities. 


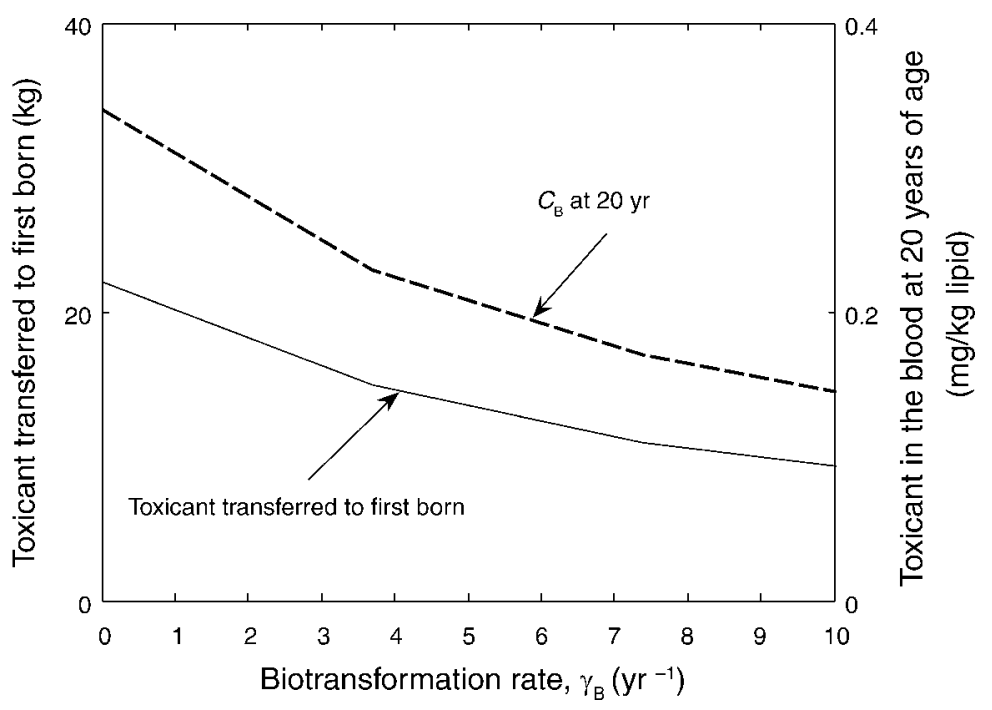

FIG. 8. Plot of toxicant transferred to the first born (left axis) and $C_{\mathrm{L}}$, the toxicant concentration in energy storage lipids at 20 years of age (right axis) for $\gamma_{\mathrm{B}}$, the biotransformation rate, ranging from 0 to $10 \mathrm{yr}^{-1}$. Toxicant transfer to later-born calves follows the same trend as for the first born, and toxicant concentrations at other ages follow the same trend as the one for 20 years of age.

lipids account for up to $13 \%$ of the total lipids $\left(e_{\mathrm{S}_{0}}<\right.$ $4.18 \times 10^{6} \mathrm{~kJ} / \mathrm{m}^{3}$ ): the age to maturity increases by a year because more lipids have to be accumulated prior to reproduction, and concentrations of toxicants decrease by $50 \%$ because a greater proportion of the body is in the form of lipids. Consequently, the vertical transfer to the first three calves decreases, but by the fourth calf, transfer effectively equilibrates with bioaccumulation and is the same as if we ignored structural lipids.

Small $\gamma_{\mathrm{B}}$ does not perceptibly influence the analysis. The estimates of the biotransformation rates of PCBs are low: 0.05-0.08 $\mathrm{yr}^{-1}$ for beluga whales (Hickie et al. 1997), and 0.2-0.4 $\mathrm{yr}^{-1}$ in humans (Phillips et al. 1989). The individual toxicant concentrations and the vertical toxicant transfer are nearly linear functions of $\gamma_{\mathrm{B}}$ and environmental toxicant concentration $\left(C_{\mathrm{I}}\right)$, even when $\gamma_{\mathrm{B}}$ is as large as $5 \mathrm{yr}^{-1}$ (Fig. 8). At rates of biotransformation comparable to those of PCBs, individual toxicant concentrations and toxicant transfer are practically the same as those without biotransformation. Even biotransformation rates on the order of months $\left(\gamma_{\mathrm{B}} \approx 10\right)$ change the bioaccumulation and toxicant transfer by less than $50 \%$.

\section{Discussion}

Understanding the processes of accumulation, partitioning, and vertical transfer of toxic substances is a necessary step towards quantifying impacts of exposure to contaminants on individuals and, in turn, populations. The lipids are by far the largest pool of energy, the largest storage depot of lipophilic toxicants, and the main vector of vertical toxicant transfer in marine mammals. Our model predicts the storage and utilization of lipids for a given energy intake, and calculates the associated toxicant dynamics. For a specified energy availability and lipid-normalized concentration of toxicants in the environment, it predicts the size and energy reserves of an individual as a function of age, and the lipid-normalized concentrations of toxicants in the three main reservoirs: blood, lipid energy storage, and structural lipids. When applied to the right whale, the model captures many life history parameters, such as age to maturity, calving intervals, and the dynamics of starvation, remarkably well. The approach-and most of the results - are applicable to other marine mammals and, more generally, other mammalian species that utilize mostly lipids for energy storage. The analyses performed in this study make the following predictions:

1) The typical energy availability experienced by the right whales (estimated from observed calving intervals), leads to a first parturition time of seven years for the North Atlantic, and six years for the southern right whales.

2) A difference in feeding rates (characterized by the model parameter $f$ ) of only $10 \%$ accounts for the difference in first parturition times and calving intervals between North Atlantic and southern right whales.

3) Seasonal variability significantly increases age at first parturition and calving intervals at low values of $f$, but has a very limited effect for large values of $f$.

4) At low $f$, the timing of seasonal variability relative to reproductive season influences the maturation time and calving interval.

5) Reproduction depends on past, as well as current energy availability (see the discussion on the calving interval hysteresis in Results). This is partly because we assume that growth is limited by the ability to meet maintenance requirements, rather than genetics. Calving hysteresis depends on the degree to which this assumption holds for a particular species. 
6) Lower energy availability increases the toxicant concentrations and vertical transfer of toxicants.

7) Contrary to expectations (e.g., Aguilar and Borrel 1994, Hickie et al. 2000, Wells et al. 2005), the firstborn calf does not necessarily receive the greatest burden. Energy availability determines the balance between bioaccumulation and dilution-by-growth of the mother's lipid energy storage after weaning, thus determining the relationship between birth order and burden received.

8) Biotransformation does not measurably influence toxicant concentrations and vertical transfer of persistent lipophilic toxicants (such as PCBs).

9) Right whale mothers lose about $40-45 \%$ of their toxicant burden during a reproductive event, and right whale calves assimilate about $30 \%$ of their mother's burden during gestation and nursing.

The quantitative predictions of results 1,2 , and 9 are specific to right whales, but they suggest that small changes in energy availability could have a big impact on reproduction of any marine mammal whose reproduction is limited by the food supply. Further reductions in food supply expose them to additional risks: increased toxicant exposure (result 6), increased exposure with birth order (result 7), decreased ability to buffer seasonal fluctuations (result 3), and increased susceptibility to temporal shifts in peak energy availability (result 4).

We believe the surprising result 7 is a consequence of the relationship between age of first parturition and calving interval, not an artifact of the model structure. The longer the calving intervals, the more mothers can bioaccumulate. The first reproductive event may energetically be easier to achieve than the second one because the individual is smaller and can spend more of its energy intake on building up the energy reserves necessary for reproduction. Therefore, it may take much longer to recuperate from a reproductive event than to have the first calf, giving time for the mother to bioaccumulate between reproductive events more than it unloaded in the prior reproductive event. Then, the later-born individual receives a larger burden.

The time scales at which lipids respond to environmental forcing have implications for sampling procedures. Blubber biopsies mainly include energy storage lipids, but can include a significant portion of structural lipids as well (Aguilar and Borrell 1990). Since the concentration in the blood during starvation increases more rapidly than the concentration in the energy storage lipids, measuring toxicant concentration in energy storage lipids can underestimate the toxicant concentration in the blood and the resulting organ exposure. This underestimate can be exacerbated if the biopsy includes a significant proportion of structural lipids because they are even slower to react to changes of concentrations in the blood.

The biotransformation of persistent toxicants can be ignored in some analyses (result 8), but if the metabolites are responsible for the toxic effect, the analysis may require inclusion of biotransformation. If the dynamics of the metabolites are important, another compartment with the metabolites as a state variable should be added to the model. Depending on the toxicant and the question at hand, including a sub-model taking preferential assimilation of toxicants (e.g., using the octanolwater partitioning coefficient, $K_{\mathrm{OW}}$ ), and respiratory exchange (e.g., using the octanol-air partitioning coefficient, $K_{\mathrm{OA}}$ ) may be required as well (see Hickie et al. [2000], and deBruyn et al. [2005] for examples).

According to our model, individuals grow larger and reproduce more frequently when food is more abundant. The calving hysteresis (result 5) suggests that growing during times of abundance may not increase reproduction in the long run if the periods of abundance are short and infrequent. Therefore, losing the ability to grow at a mature age may result in more offspring: although organisms are not able to fully utilize years of abundance because of their smaller size, they make up for it during the times of scarcity. In such environments, cessation of growth may offer a competitive advantage over indeterminate growth.

It is advantageous to give birth at the onset of seasonal food scarcity (result 4). This contrasts with organisms that benefit from abundance at the earliest stages of the development (Klanjscek et al. 2006). Further research could help explain the timing of reproduction of marine mammals relative to seasonal cycles of food.

Linking observables such as copepod density to $e_{\mathrm{I}}$ and the energy intake is a daunting task, but our analyses does not depend on the correct interpretation of $e_{\mathrm{I}}$ because we were concerned with the energy intake, which is a linear function of $I_{\max }$ and $f$. Therefore, a small underestimate of $I_{\max }$ can be compensated for by a small overestimate of $f$. Translating the differences in $f$ into differences in $e_{\mathrm{I}}$, however, highly depends on the value of $I_{\max }$. Our current estimate of $I_{\max }$ and $K_{\mathrm{I}}$ imply that $e_{\mathrm{I}}$ experienced by the North Atlantic right whale is about an order of magnitude lower than $e_{\mathrm{I}}$ experienced by the southern right whale. Even though such differences in copepod densities are often observed (Wishner et al. 1988, Mayo and Marx 1990, Beardsley et al. 1996, Baumgartner et al. 2003), they cannot be directly translated into changes in $e_{\mathrm{I}}$ because these changes depend on the value of other energy intake parameters. For example, our estimate of $e_{\mathrm{I}}$ comes from $f$ of 0.9 in the Atlantic, and 0.99 in the southern seas. If $I_{\max }$ were $10 \%$ higher, $f$ experienced by the Northern Atlantic right whale would have been 0.82 , and that of the southern whale 0.9: still a $10 \%$ difference in $f$, but only a twofold difference in $e_{\mathrm{I}}$ due to the nonlinearity of the functional response. Therefore, the interpretation of $e_{\mathrm{I}}$ depends on the estimate of $I_{\max }$ and $K_{\mathrm{I}}$. To better estimate these parameters, we would need to incorporate variable costs of foraging, and much more information on spatially explicit copepod dynamics and right whale distribution than is available at this time. Alternatively, given a population model based on this individual 
model, we could fit these parameters to observations of right whale population dynamics and copepod abundance.

The calculated ages to first parturition of seven and six years, for North Atlantic and southern populations, respectively, are significantly smaller than estimates of $9.5 \pm 2.32$ years (mean $\pm \mathrm{SD}$ ) for the North Atlantic (Kraus et al. 2001) and $8.5 \pm 2$ years for the southern right whales (Best et al. 2001). However, the average estimates may be inflated by variable environmental conditions, miscarriages, or lack of fertilization, none of which are included in the simulations; ages at first parturition as low as five years have been observed in the North Atlantic (Knowlton et al. 1994).

Our model can help determine the reproductive costs of anthropogenic feeding interruptions. This could help guide the policy on whale watching, and the use of alarms to reduce ship strike mortality by inducing collision-avoidance responses in the whales (Nowacek et al. 2004). The reduction in energy intake due to feeding interruptions can be represented by reducing $I_{\max }$. Reducing $I_{\max }$ of Northern Atlantic right whales by only $16 \%$ is equivalent to reducing $f$ to 0.75 , making reproduction impossible (Fig. 4). Quantifying these costs of feeding interruptions could help balance them with economic and demographic benefits of feeding interruptions. Before quantifying such predictions, further exploration of the model is necessary.

Our model is defined by the compartment structure in Fig. 1, the dynamic equations for those compartments in Table 2, the flux relationships in Table 3, and, for the right whale application, the parameter values in Table 4. Each of these successively more specific levels involves, as it should, simplifications and approximations. Each can be criticized and tested against experimental measurements (e.g., is the intake of energy into blood truly proportional to $V^{2 / 3}$, or is it better described by some other function?). And, most important, each could be further simplified, or further elaborated. There is no single model.

A measure of the success of any model, ours included, is the extent to which the combination of model structure, dynamic equations, and parameter values produces results that are (1) interesting and (2) not imposed a priori by the model. Even in our first exploration, our model has produced several such results: (1) the value of $f$ that yields observed calving intervals also yields observed whale sizes although there is no a priori reason to do so; (2) the difference in food levels calculated to explain the observed difference in calving intervals also explains the observed difference in first parturition times; (3) the relationship between first parturition time and calving interval agrees with observations, even though neither of those times were explicitly included in the structure of the model; and (4) the predicted bioaccumulation matches empirical patterns and concentrations, even though toxicological and energetics parameters were estimated independently of each other and of the data.

Adapting the model to other marine mammal species involves adapting the structure of the energetics and the pharmacokinetics parts of the model, linking them, and estimating the parameters. Blood, structure, and energy reserves are crucial to the formulation of the energetics part of the model, but the modular and hierarchical structure of the model allows for adaptations to the model dictated by the processes important for the species and questions of interest. We linked the energetics and pharmacokinetic parts of the model assuming that lipid dynamics drives toxicant transport. For lipophilic toxicants, this may be sufficient; for others, different approaches - possibly even additional compartments - may be necessary. Additional compartments are necessary to distinguish between types of lipids. The need to do so, however, depends on the significance of the different types of lipids in the particular species, and toxicological questions of interest. Our results suggest that, to predict the patterns of bioaccumulation and vertical transfer, structural lipids can be omitted if they constitute less than $5 \%$ of the total lipids.

Estimating the percentage of structural lipids is difficult. Starvation studies on Harbor Porpoises (Phocoena phocoena) suggest that less then half of the lipids are readily metabolized (Koopman et al. 2002). This does not imply that all the remaining blubber is structural because death by starvation happens when the flux from the energy reserves cannot meet maintenance; the flux becomes insufficient before the reserves disappear. Depending on its physiology (e.g., if $\beta_{\mathrm{L}}$ or $k_{\mathrm{L}}$ is low), an animal can die of starvation with ample reserves left.

Blubber morphology can help distinguish structural from energy storage blubber. For example, high proportion of collagen in blubber (Pond 1987), low vascularization (Struntz et al. 2004), and negligible responses to physiological condition of the animal (Aguilar and Borrell 1990, Koopman et al. 2002) suggest structural blubber. The overall proportions of structural and energy storage lipids are, however, largely unknown.

Running the model requires all parameters listed in Table 4 , as well as the energy availability $(f)$ to characterize the environment. Rather than tuning the parameters to fit the outputs of the model to observations, we estimated them using physiological considerations and morphometric data. To do that, we needed to derive and rely heavily on the relationship between length and structural volume of right whales. This relationship may be a good approximation for other species, but we believe the parameters in the relationship are species-specific. Likewise, some estimates $\left(\beta_{\mathrm{L}}, \beta_{\mathrm{G}}, g\right.$, $\gamma_{\mathrm{B}}$, and $\left.D_{\mathrm{LS}}\right)$ may hold for most marine mammals, but the rest are probably species-specific. There is theory that characterizes interspecific variation in model 
parameters for simpler energy budget models (Kooijman 2000). A challenge for theorists is to develop analogous insight applicable to more complex models, like ours, that share many assumptions with their simpler counterparts.

Our model describes the responses of individuals, not populations, to environmental fluctuations. Nevertheless, the conclusions have implications for populations. For example, if energy availability is low for a long time and then increases, a baby boom can be expected. Greene et al. (2003) observe such correlations (see also Kenney et al. 2001), and suggest that the North Atlantic oscillation (NAO) is the main predictor of calving success (see also Fujiwara and Caswell 2001). Our model provides a mechanistic link between the environment and the individual, but needs a population model to investigate consequences on the population dynamics.

Similarly, when toxicant concentrations fluctuate, bioaccumulation, vertical transfer, and export of toxicants out of the population through death may influence the exposure of individuals. Quantifying that response, however, requires a population model in conjunction with a toxicant action model to account for effects of exposure on individuals. These effects can be included through exposure-dependent modifications of model parameters, for example through foraging ability or maintenance costs (Nisbet et al. 1997). We are formulating population models based on the individual model presented here to address such questions.

\section{ACKNOWLedgments}

We thank Michael Moore for lending us his expertise on marine mammal life history and Mark Hahn for his insights in toxicology. We also thank Erik Noonburg for insights on dynamic energy budget models, Mark F. Baumgartner and Peter Tyack for their help with marine mammal energetics, and Eric Montie for discussions on blubber function and morphology. This research was supported by the David and Lucile Packard Foundation, the U.S. National Science Foundation (DEB-9973518 and OCE-0083976), the U.S. Environmental Protection Agency (R-82908901-0), NOAA grant NA03NMF4720491, and the WHOI/MIT Joint Program in Oceanography.

\section{Literature Cited}

Aguilar, A., and A. Borrell. 1990. Patterns of lipid content and stratification in the blubber of fin whales (Balaenoptera physalus). Journal of Mammalogy 71:544-554.

Aguilar, A., and A. Borrell. 1994. Reproductive transfer and variation of body load of organochlorine pollutants with age in fin whales (Balaenoptera physalus). Archives of Environmental Contamination and Toxicology 27:546-554.

Aguilar, A., A. Borrell, and T. Pastor. 1999. Biological factors affecting variability of persistent pollutant levels in cetaceans. Journal of Cetacean Research and Management Special Issue 1:83-116.

Angell, C. 2005. Body fat condition of right whales, Eubalaena glacialis and Eubalaena australis. Dissertation. Boston University, Boston, Massachusetts, USA.

Baumgartner, M. F., T. V. N. Cole, R. G. Campbell, G. J. Teegarden, and E. G. Durbin. 2003. Associations between north Atlantic right whales and their prey, Calanus finmarchicus, over diel and tidal time scales. Marine Ecological Progress Series 264:155-166.
Beardsley, R. C., A. W. Epstein, C. Chen, K. F. Wishner, M. C. Macaulay, and R. D. Kenney. 1996. Spatial variability in zooplankton abundance near feeding right whales in the great south channel. Deep-Sea Research Part II, Topical Studies in Oceanography 43:1601-1625.

Best, P. B., A. Brandao, and D. S. Butterworth. 2001. Demographic parameters of southern right whales off south Africa. Journal of Cetacean Research and Management, Special Issue 2:161-169.

Best, P. B., and D. M. Schell. 1996. Stable isotopes in southern right whale (Eubalaena australis) baleen as indicators of seasonal movements, feeding and growth. Marine Biology 124:483-494

Boon, J., I. Oostingh, J. van der Meer, and T. Hillebrand. 1994. A model for the bioaccumulation of chlorobiphenyl congeners in marine mammals. European Journal of Pharmacology: Environmental Toxicology and Pharmacology 270:237251.

Boon, J. P., E. van Arnhem, S. Jansen, N. Kannan, G. Petrick, D. Schulz, J. Duinker, P. Reijnders, and A. Goksoyr. 1992. The toxicokinetics of PCBs in marine mammals with special reference to possible interactions of individual congeners with the cytochrome P450-dependent monooxygenase system: an overview. Pages 119-160 in C. H. Walker and D. R. Livingstone, editors. Persistent pollutants in marine ecosystems. Pergamon Press, Oxford, UK.

Borga, K., A. Fisk, P. Hoekstra, and D. Muir. 2004. Biological and chemical factors of importance in the bioaccumulation and trophic transfer of persistent organochlorine contaminants in Arctic marine food webs. Environmental Toxicology and Chemistry 23:2367-2385.

Bronson, F., and J. Manning. 1991. The energetic regulation of ovulation: a realistic role for body fat. Biology of Reproduction 44:945-950.

Brownell, R. L., Jr., P. J. Clapham, T. Miyashita, and T. Kasuya. 2001. Conservation status of North Pacific right whales. Journal of Cetacean Research and Management, Special Issue 2:269-286.

Brunell, S. R. 2001. Aspects of the reproductive biology, movement and site fidelity of right whales off Australia. Journal of Cetacean Research and Management, Special Issue 2:89-99.

Convention, W. 1931. Convention for the regulation of whaling, Geneva. League of Nations Treaty Series 155:349-365.

Crank, J. 2004. The mathematics of diffusion. Second edition. Oxford University Press, Oxford, UK.

deBruyn, A. M., M. G. Ikonomou, and F. A. Gobas. 2005. Magnification and toxicity of PCBs, PCDDs, and PCDFs in upriver-migrating Pacific Salmon. Environmental Science and Technology 38:6217-6224.

de Swart, R. L., P. S. Ross, L. J. Vedder, H. H. Timmerman, S. Heisterkamp, H. Van Loveren, J. G. Vos, P. J. H. Reijnders, and A. D. M. E. Osterhaus. 1994. Impairment of immune function in harbour seals (Phoca vitulina) feeding on fish from polluted waters. Ambio 23:155-159.

Frisch, R. 1978. Population, food intake, and fertility. Science 199:22-30.

Frisch, R. 1990. The right weight: body fat, menarche and ovulation. Bailliere's Clinical Obstetrics and Gynaecology 4: 419-439.

Frisch, R., D. Hegsted, and K. Yoshinaga. 1975. Body weight and food intake at early estrus of rats on a high-fat diet. Proceedings of the National Academy of Sciences (USA) 72: 4172-4176.

Fujiwara, M., and H. Caswell. 2001. Demography of the endangered North Atlantic right whale. Nature 414:537-541.

Gopalan, C., and A. Naidu. 1972. Nutrition and fertility. Lancet 2:1077-1079.

Greene, C., A. Pershing, R. Kenney, and J. Jossi. 2003. Impact of climate variability on the recovery of endangered North Atlantic right whales. Oceanography 16:98-103. 
Guo, Y., G. Lambert, C. C. Hsu, and M. M. Hsu. 2004. Yucheng: health effects of prenatal exposure to polychlorinated biphenyls and dibenzofurans. International Archives of Occupational and Environmental Health 77:153-158.

Gurney, W. S. C., E. McCauley, R. M. Nisbet, and W. W. Murdoch. 1990. The physiological ecology of daphnia: a dynamic model of growth and reproduction. Ecology 71:716732.

Gurney, W. S. C., and R. M. Nisbet. 1998. Ecological dynamics. Oxford University Press, New York, New York, USA.

Gurney, W. S. C., and R. M. Nisbet. 2004. Resource allocation, hyperphagia and compensatory growth. Bulletin of Mathematical Biology 66:1731-1753.

Hallam, T. G., R. R. Lassiter, J. Li, and L. A. Suarez. 1990. Modelling individuals employing an integrated energy response: application to daphnia. Ecology 71:938-954.

Hickie, B. E., M. C. S. Kingsley, P. V. Hodson, D. C. G. Muir, P. Beland, and D. Mackay. 2000. A modelling-based perspective on the past, present, and future polychlorinated biphenyl contamination of the St. Lawrence 800 beluga whale (Delphinapterus leucas) population. Canadian Journal of Fisheries and Aquatic Sciences 57:101-112.

Hickie, B. E., D. Mackay, and J. De Koning. 1999. Lifetime pharmacokinetic model for hydrophobic contaminants in marine mammals. Environmental Toxicology and Chemistry 18:2622-2633.

Hickie, B., D. Mackay, and D. Muir. 1997. Use of novel pharmacokinetic models to estimate contaminant elimination rates in marine mammals. 18th Annual Meeting of the Society of Environmental Toxicology and Chemistry, San Francisco, California. SETAC Press, Pensacola, Florida, USA.

Iverson, S. 2002. Blubber. Pages 107-112 in W. F. Perrin, B. G. Wuersig, and J. G. M. Thewissen, editors. Encyclopedia of marine mammals. Academic Press, San Diego, California, USA.

Jørgensen, E., B. Bye, and M. Jobling. 1999. Influence of nutritional status on biomarker responses to $\mathrm{PCB}$ in the arctic charr (Salvelinus alpinus). Aquatic Toxicology 44:233244.

Kenney, R. D., C. A. Mayo, and H. E. Winn. 2001. Migration and foraging strategies at varying spatial scales in western North Atlantic right whales: a review of hypotheses. Journal of Cetacean Research and Management, Special Issue 2:251260.

Klanjscek, T., H. Caswell, M. G. Neubert, and R. M. Nisbet. 2006. Integrating dynamic energy budgets into matrix population models. Ecological Modelling 196:407-420.

Knowlton, A. R., S. D. Kraus, and R. D. Kenney. 1994. Reproduction in North-Atlantic right whales (Eubalaena glacialis). Canadian Journal of Zoology 72:1297-1305.

Kooijman, S. A. L. M. 2000. Dynamic energy and mass budgets in biological systems. Second edition. Cambridge University Press, Cambridge, UK.

Koopman, H. N., D. A. Pabst, W. A. McLellan, R. M. Dillaman, and A. J. Read. 2002. Changes in blubber distribution and morphology associated with starvation in the harbor porpoise (Phocoena phocoena): evidence for regional differences in blubber structure and function. Physiological and Biochemical Zoology 75:498-512.

Kraus, S. D., P. K. Hamilton, R. D. Kenney, A. R. Knowlton, and C. K. Slay. 2001. Reproductive parameters of the North Atlantic right whale. Journal of Cetacean Research and Management, Special Issue 2:231-236.

Lee, J. S., S. Tanabe, H. Umino, R. Tatsukawa, D. C. Loughlin, and T. R. Calkins. 1996. Persistent organochlorines in Steller sea lion (Eumetopias jubatus) from the bulk of Alaska and the Bering Sea, 1976-1981. Marine Pollution Bulletin 32:535-544.
Lee, P. 1987. Nutrition, fertility and maternal investment in primates. Journal of Zoology (London) 213:409-422.

Leung, H., D. Paustenbach, F. Murray, and M. Andersen. 1990a. A physiological pharmacokinetic description of the tissue distribution and enzyme-inducing properties of 2,3,7,8tetrachlorodibenzo-p-dioxin in the rat. Toxicology and Applied Pharmacology 103:399-410.

Leung, H., A. Poland, D. Paustenbach, F. Murray, and M. Andersen. 1990b. Pharmacokinetics of [125i]-2-iodo-3,7,8trichlorodibenzo-p-dioxin in mice: analysis with a physiological modeling approach. Toxicology and Applied Pharmacology 103:411-419.

Lika, K., and R. M. Nisbet. 2000. A dynamic energy budget model based on partitioning of net production. Journal of Mathematical Biology 41:361-386.

Lockyer, C. 1976. Body weights of some species of large whales. Journal du Conseil International pour l'Exploration de la Mer 36:259-273.

Lockyer, C. 1986. Body fat condition in northeast Atlantic fin whales, Balaenoptera physalus, and its relationship with reproduction and food resource. Canadian Journal of Fisheries and Aquatic Sciences 43:142-147.

Martin, R. D., and A. M. MacLarnon. 1985. Gestation period, neonatal size and maternal investment in placental mammals. Nature 313:220-223.

Martineau, D., K. Lemberger, A. Dallaire, P. Labelle, T. P. Lipscomb, P. Michel, and I. Mikaelian. 2002. Cancer in wildlife, a case study: beluga from the St. Lawrence estuary, Quebec, Canada. Environmental Health Perspectives 110: 285-292.

Mayo, C. A., and M. K. Marx. 1990. Surface foraging behaviour of the North Atlantic right whale, Eubalaena glacialis, and associated zooplankton characteristics. Canadian Journal of Zoology 68:2214-2220.

McCauley, E., W. Murdoch, R. Nisbet, and W. Gurney. 1990. The physiological ecology of daphnia I: development of a model of growth and reproduction. Ecology 71:703-715.

Moore, J., A. Knowlton, S. Kraus, W. McLellan, and R. Bonde. 2005. Morphometry, gross morphology and available histopathology in North Atlantic right whale (Eubalaena glacialis) mortalities (1980-2002). Journal of Cetacean Research and Management 6:199-214.

Muller, E. B., and R. M. Nisbet. 1997. Modeling the effect of toxicants on the parameters of dynamic energy budget models, in ASTM Special Technical Publication. ASTM, Conshohocken, Pennsylvania, USA.

Nisbet, R. M., S. Diehl, W. G. Wilson, S. D. Cooper, D. D. Donalson, and K. Kratz. 1997. Primary-productivity gradients and short-term population dynamics in open systems. Ecological Monographs 67:535-553.

Nisbet, R. M., E. B. Muller, K. Lika, and S. A. L. M. Kooijman. 2000. From molecules to ecosystems through dynamic energy budget models. Journal of Animal Ecology 69:913-926.

Noonburg, E. G., R. M. Nisbet, E. McCauley, W. S. C. Gurney, W. W. Murdoch, and A. M. De Roos. 1998. Experimental testing of dynamic energy budget models. Functional Ecology 12:211-222.

Nordoy, E. S., and A. S. Blix. 1985. Energy sources in fasting grey seal pups evaluated with computed tomography. American Journal of Physiology: Regulatory, Integrative and Comparative Physiology 249:471-476.

North Atlantic Right Whale Recovery Team. 2000. Canadian recovery plan for the North Atlantic right whale. World Wildlife Fund Canada and the Department of Fisheries and Oceans, Toronto, Ontario, Canada.

Nowacek, D., M. Johnson, and P. Tyack. 2004. North Atlantic right whales (Eubalaena glacialis) ignore ships but respond to alerting stimuli. Proceedings of the Royal Society of London, Series B 271:227-231. 
Phillips, D. L., A. B. Smith, V. W. Burse, G. K. Steele, L. L. Needham, and W. H. Hannon. 1989. Half-life of polychlorinated biphenyls in occupationally exposed workers. Archives of Environmental Health 44:351-354.

Pond, C. M. 1987. Some conceptual and comparative aspects of body composition analysis. Pages 499-529 in F. M. Toates and N. Rowland, editors. Methods and techniques to study feeding and drinking behaviour. Elsevier, Amsterdam, The Netherlands.

Porter, W. P., S. Budaraju, W. E. Stewart, and N. Ramankutty. 2000. Calculating climate effects on birds and mammals: Impacts on biodiversity, conservation, population parameters, and global community structure. American Zoologist 40:597-630.

Porter, W., J. Sabo, C. Tracy, O. Reichman, and N. Ramankutty. 2002. Physiology on a landscape scale: plantanimal interactions. Integrative and Comparative Biology 42: 431-453.

Reeves, R. R., J. M. Breiwick, and E. Mitchell. 1992. Preexploitation abundance of right whales off the eastern United States. Pages 5-7 in J. Hain, editor. Right whales in the western North Atlantic: a management workshop. Northeast Fisheries Science Center Reference Document No. 92-05. NEFSC/NMFS, Woods Hole, Massachusetts, USA.

Reijnders, P. J. H. 1986. Reproductive failure in common seals feeding on fish from polluted coastal waters. Nature 324:456457.

Reilly, J. J. 1991. Adaptations to prolonged fasting in freeliving weaned gray seal pups. American Journal of Physiology-Regulatory, Integrative and Comparative Physiology 260:267-272.

Restum, J., S. Bursian, J. Giesy, J. Render, W. Helferich, E. Shipp, D. Verbrugge, and R. Aulerich. 1998. Multigenerational study of the effects of consumption of PCB-contaminated carp from Saginaw Bay, Lake Huron, on mink. 1. Effects on mink reproduction, kit growth and survival, and selected biological parameters. Journal of Toxicology and Environmental Health A 54:343-375.

Rosenbaum, H. C., et al. 2000. World-wide genetic differentiation of Eubalaena: questioning the number of right whale species. Molecular Ecology 9:1793-1802.

Ross, A. H., and R. M. Nisbet. 1990. Dynamic models of growth and reproduction of the mussel Mytilus edulis 1 . Functional Ecology 4:777-787.

Ross, P. S., R. L. De Swart, R. F. Addison, H. Van Loveren, J. Vos, and A. Osterhaus. 1996. Contaminant-induced immunotoxicity in harbour seals: wildlife at risk? Toxicology 112(2):157-169.
Ross, P. S., G. M. Ellis, M. G. Ikonomou, L. G. BarrettLennard, and R. F. Addison. 2000. High PCB concentrations in freeranging Pacific killer whales, Orcinus orca: effects of age, sex and dietary preference. Marine Pollution Bulletin 40: 504-515.

Schwacke, L. H., E. O. Voit, L. J. Hansen, R. S. Wells, G. B. Mitchum, A. A. Hohn, and P. A. Fair. 2002. Probabilistic risk assessment of reproductive effects of polychlorinated biphenyls on bottlenose dolphins (Tursiops truncatus) from the southeast United States coast. Environmental Toxicology and Chemistry 21:2752-2764.

Struntz, D. J., W. A. McLellan, R. M. Dillaman, J. E. Blum, J. R. Kucklick, and D. Pabst. 2004. Blubber development in bottlenose dolphins (Tursiops truncatus). Journal Morphology 259:7-20.

Thomas, P. O., and S. M. Taber. 1984. Mother-infant interaction and behavioral development in southern right whales, Eubalaena australis. Behaviour 88:42-46.

Thomas, P. T., and R. D. Hinsdill. 1980. Perinatal PCB exposure and its effect on the immune system of young rabbits. Drug and Chemical Toxicology 3:173-184.

Van der Spuy, Z. 1985. Nutrition and reproduction. Bailliere's Clinical Obstetrics and Gynaecology 12:579-604.

von Bertalanffy, L. 1957. Quantitative laws in metabolism and growth. Quarterly Review of Biology 32:217-231.

Weisbrod, A. V., D. Shea, M. J. Moore, and J. J. Stegeman. 2000. Organochlorine exposure and bioaccumulation in the endangered northwest Atlantic right whale (Eubalaena glacialis) population. Environmental Toxicology and Chemistry 19:654-666.

Wells, R., V. Tornero, A. Borrell, A. Aguilar, T. Rowles, H. Rhinehart, S. Hofmann, W. Jarman, A. Hohn, and J. Sweeney. 2005. Integrating life-history and reproductive success data to examine potential relationships with organochlorine compounds for bottlenose dolphins (Tursiops truncatus) in Sarasota Bay, Florida. Science of the Total Environment. 349:106-119.

Winn, H. E., C. A. Price, and P. W. Sorensen. 1986. The distributional biology of the right whale (Eubalaena glacialis) in the western North Atlantic. Report of the International Whaling Commission, Special Issue 10:129-138.

Wishner, K., E. Durbin, A. Durbin, M. Macaulay, H. Winn, and R. Kenney. 1988. Copepod patches and right whales in the great south channel off New England. Bulletin of Marine Science 43:825-844.

Young, R. 1976. Fat, energy and mammalian survival. American Zoologist 16:699-710.

\section{APPENDIX}

Right whale dynamic energy budget model parameter estimation and morphometrics (Ecological Archives A017-092-A1). 